\title{
Microwave Specular Measurements and Ocean Surface Wave Properties
}

\author{
Paul A. Hwang *(D), Thomas L. Ainsworth and Jeffrey D. Ouellette \\ Remote Sensing Division, U.S. Naval Research Laboratory, Washington, DC 20375, USA; \\ ainsworth@nrl.navy.mil (T.L.A.); jeffrey.ouellette@nrl.navy.mil (J.D.O.) \\ * Correspondence: paul.hwang@nrl.navy.mil
}

check for updates

Citation: Hwang, P.A.; Ainsworth, T.L.; Ouellette, J.D. Microwave Specular Measurements and Ocean Surface Wave Properties. Sensors 2021, 21, 1486. https://doi.org/10.3390/ s21041486

Academic Editor: Ali Khenchaf

Received: 29 December 2020

Accepted: 17 February 2021

Published: 20 February 2021

Publisher's Note: MDPI stays neutral with regard to jurisdictional claims in published maps and institutional affiliations.

Copyright: (c) 2021 by the authors. Licensee MDPI, Basel, Switzerland. This article is an open access article distributed under the terms and conditions of the Creative Commons Attribution (CC BY) license (https:/ / creativecommons.org/licenses/by/ $4.0 /)$.

\begin{abstract}
Microwave reflectometers provide spectrally integrated information of ocean surface waves several times longer than the incident electromagnetic (EM) wavelengths. For high wind condition, it is necessary to consider the modification of relative permittivity by air in foam and whitecaps produced by wave breaking. This paper describes the application of these considerations to microwave specular returns from the ocean surface. Measurements from $\mathrm{Ku}$ and $\mathrm{Ka}$ band altimeters and $\mathrm{L}$ band reflectometers are used for illustration. The modeling yields a straightforward integration of a closedform expression connecting the observed specular normalized radar cross section (NRCS) to the surface wave statistical and geometric properties. It remains a challenge to acquire sufficient number of high-wind collocated and simultaneous reference measurements for algorithm development or validation and verification effort. Solutions from accurate forward computation can supplement the sparse high wind databases. Modeled specular NRCSs are provided for L, C, X, Ku, and Ka bands with wind speeds up to $99 \mathrm{~m} / \mathrm{s}$.
\end{abstract}

Keywords: ocean surface roughness; normalized radar cross section; specular reflection; relative permittivity; whitecaps

\section{Introduction}

The range of ocean surface wavelengths important to microwave remote sensing extends several orders of magnitude. Crombie [1] reports the Doppler frequency spectrum of $13.56 \mathrm{MHz}$ radar sea echo at low grazing angle. A distinct spectral peak at $0.38 \mathrm{~Hz}$ is illustrated, corresponding to the resonance ocean surface wavelength of about $10 \mathrm{~m}$ (wavenumber $k$ about $0.6 \mathrm{rad} / \mathrm{m}$ ). He goes on to suggest that variable frequency equipment can be used to measure the ocean surface wave spectrum. Depending on frequency and incidence angle, the range of resonance surface wavenumbers spans from about $20 \mathrm{rad} / \mathrm{m}$ ( $\mathrm{L}$ band) to about $500 \mathrm{rad} / \mathrm{m}$ (Ku band) for microwave sensors operating at moderate and high incidence angles $[2,3]$.

For altimeters and reflectometers, the specular reflection mechanism dominates. The NRCS is proportional to the number of specular points and the average radii of curvature of the specular reflection facets [4-6]. With the Gaussian distribution describing the elevation and slope of the moving ocean surface [7], a simple inverse relationship between NRCS and surface mean square slope (MSS) is established [5,6]. Further analysis [8-10] indicates that the responsible MSS is contributed by surface waves longer than the EM wavelengths. The frequently cited ratio between the EM wavenumber $k_{r}$ and the upper cutoff wavenumber $k_{u}$ of Low-Pass MSS (LPMSS) integration is between 3 and 6 [9,10]. Thus, for Ku band $(\sim 14 \mathrm{GHz})$ altimeter, $k_{u}$ is about 50 to $100 \mathrm{rad} / \mathrm{m}$, and for L band ( 1.6 GHz) reflectometer it is about 6 to $11 \mathrm{rad} / \mathrm{m}$.

These theoretical and empirical analyses provide useful guidelines for quantitative investigation of the connection between specular NRCS and ocean surface roughness. $\mathrm{Ku}$ band altimeters have been in operation for many decades, and there is a rich trove of well-calibrated $\mathrm{Ku}$ band altimeter NRCS data for a close examination of the specular 
point theory (SPT) applied to nadir-looking altimeters: $\sigma_{0}=|R(0)|^{2} / s_{f}^{2}$, where $\sigma_{0}$ is NRCS, $R(0)$ is the Fresnel reflection coefficient for normal incidence, and $s_{f}^{2}$ is the Ku band LPMSS [8-10]. One peculiar outcome is that the resulting $s_{f}^{2}$ calculated from measured $\mathrm{Ku}$ band NRCS is larger than the optical total MSS [11,12]. The difference is especially obvious in low and moderate wind speeds $\left(U_{10}\right.$ less than about $\left.10 \mathrm{~m} / \mathrm{s}\right)$. To address this paradox, an effective reflectivity ranging from 0.34 to 0.5 has been suggested [8-10]; those numbers are much smaller than the nominal relative permittivity of 0.62 computed for the $\mathrm{Ku}$ band frequency. An alternative explanation is that the peculiar result can be reconciled if the tilting effect of the reflecting specular facets is considered when applying the SPT $[13,14]$. It has been about two decades since the study presented in $[13,14]$ and our understanding of the ocean surface wave spectrum has advanced considerably with incorporation of remote sensing data into the relatively sparse databases of short-scale ocean surface waves accumulated from direct observations [15-17]. Here we revisit the Ku band altimeter NRCS analyses. The results are applied to other frequencies including the observations of L band LPMSS [18-21] and recent reports of NRCS results derived from the CYclone Global Navigation Satellite System (CYGNSS) mission [22-24], and Ka band altimeter NRCS from the Satellite ARgos and ALtiKa (SARAL) mission [25,26]. The overall objectives are (a) to use specular microwave returns to understand the mean square slopes of surface waves several times longer than the radar wavelengths; spaceborne altimeter and reflectometer measurements coupled with the SPT are employed for this study; and (b) to supplement the high wind in situ data with accurate forward computation of the altimeter and reflectometer solutions.

Section 2 gives a brief review of the SPT [4-6,8]. Section 3 describes its application to spaceborne microwave observations. Section 4 discusses issues such as wind speed and wave age relationship on LPMSS, whitecap effects caused by wave breaking on surface reflectivity in high winds, and extending the analysis to various frequencies. The NRCS dependence on incidence and scattering angles are presented and discussed with computed examples; the limitations and range of application are described. Section 5 is summary.

\section{Review of Specular Point Theory}

Kodis [4] presents a theoretical analysis of backscattering from a perfectly conducting 1D irregular surface at very short EM wavelengths (Kirchoff approximation), with the application of the stationary phase principle to the Kirchoff integral for the complex scattered field. The integral formulas are derived directly from the vector field theory. He shows that to the first order approximation, the backscattering cross section is proportional to the product of the average number of specular points illuminated by the EM waves $n_{A}$, and the geometric mean of the two principal radii of curvature of those specular points $r_{1}$ and $r_{2}$, i.e.,

$$
\sigma\left(k_{i},-k_{i}\right) \sim \pi\left\langle\left|r_{1} r_{2}\right|\right\rangle n_{A}
$$

where $k_{i}$ is the incidence EM wavenumber. This analysis elicits the close connection between EM scattering and statistical and geometrical properties of the rough surface. In order to carry out the calculation further, it is necessary to specify the statistics of the rough surface, in particular in regard to the average number of illuminated specular points and their average curvature.

Barrick $[5,6]$ extends the analysis to 2D horizontal plane, full scattering geometry configuration, polarization states, and finite surface conductivity. Following his notations as defined by the scattering geometry depicted in his Figure 1, which is simplified and reproduced here as Figure 1, the NRCS for arbitrary incident and scattered polarization states $\left(\eta\right.$ and $\xi$, respectively), incidence angles $\left(\theta_{i}, \phi_{i}=0\right)$, and scattering angles $\left(\theta_{s}, \phi_{s}\right)$ is

$$
\sigma_{0 \xi \eta}=\pi\left|R_{\xi \eta}(\iota)\right|^{2}\left\langle\left|r_{1} r_{2}\right|\right\rangle n_{A}
$$

where $R_{\tilde{\xi} \eta}(l)$ is the reflection coefficient from infinite plane tangent to the surface at the specular points for incidence and scattered states, and $\iota$ is the local (effective) incidence 
angle at the specular points. From Kodis's stationary phase analysis [4], it is shown that the effective incidence angle $\iota$ is half the angle between the incidence and scattering propagation directions [5], and it can be expressed as a function of incidence and scattering angles (after correcting a couple of typographic errors):

$$
\cos \iota=\left[\left(1-\sin \theta_{i} \sin \theta_{s} \cos \phi_{s}+\cos \theta_{i} \cos \theta_{s}\right) / 2\right]^{1 / 2}
$$

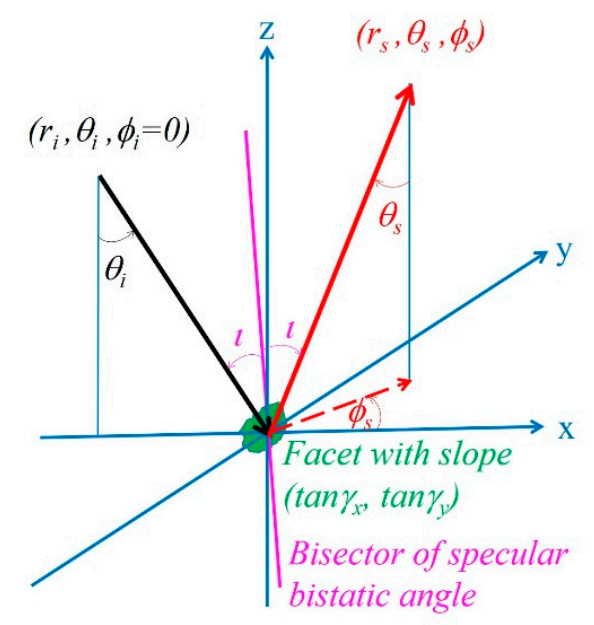

Figure 1. The scattering geometry from a surface facet.

The average number of specular points per unit area for a rough surface and the average radii of curvatures are then derived in terms of the surface statistics. Sections 2 and 3 of Barrick [5] and Appendix B of Barrick [6] give the detailed mathematical derivation of $n_{A}$ and $\left\langle\left|r_{1} r_{2}\right|>\right.$. The final results are copied here:

$$
\begin{gathered}
n_{A}=\frac{7.255}{\pi^{2} l^{2}} \exp \left(\frac{-\tan ^{2} \gamma}{s_{f}^{2}}\right) \\
\left\langle\left|r_{1} r_{2}\right|\right\rangle=\frac{0.138 \pi l^{2}}{s_{f}^{2}} \sec ^{4} \gamma
\end{gathered}
$$

where $l$ is the correlation length between surface points $\zeta(x, y)$ and $\zeta\left(x^{\prime}, y^{\prime}\right)$ separated by a horizontal distance $r=\left[\left(x-x^{\prime}\right)^{2}+\left(y-y^{\prime}\right)^{2}\right]^{1 / 2}$ and assuming a Gaussian distribution of the correlation coefficient as $r \rightarrow 0$. The numerical constants in Equations (4) and (5) result from carrying out triple integral functions of $\left(\zeta_{x x}, \zeta_{x y}, \zeta_{y y}\right)$; the details are provided in Barrick [5,6].

Substituting Equations (4) and (5) into Equation (2), then

$$
\sigma_{0 \xi \eta}=\left|R_{\xi \eta}(\iota)\right|^{2} \frac{\sec ^{4} \gamma}{s_{f}^{2}} \exp \left(\frac{-\tan ^{2} \gamma}{s_{f}^{2}}\right)
$$

where $s_{f}^{2}$ is the ocean surface LPMSS, and $\tan \gamma$ is the surface slope at the specular point, which can be expressed as a function of incidence and scattering angles.

$$
\tan \gamma=\frac{\left(\sin ^{2} \theta_{i}-2 \sin \theta_{i} \sin \theta_{s} \cos \phi_{s}+\sin ^{2} \theta_{s}\right)^{1 / 2}}{\cos \theta_{i}+\cos \theta_{s}}
$$


A case of special interest is backscattering: $\phi_{s}=\pi, \theta_{s}=\theta_{i}, \gamma=\theta_{i}$, and the NRCS is

$$
\sigma_{0 \tilde{\eta}}=\left|R_{\xi \eta}(\iota)\right|^{2} \frac{\sec ^{4} \theta_{i}}{s_{f}^{2}} \exp \left(\frac{-\tan ^{2} \theta_{i}}{s_{f}^{2}}\right)
$$

\section{Application}

\subsection{Ku Band Altimeter Analysis}

For a nadir-looking altimeter $\left(\theta_{i}=\theta_{S}=\iota=0\right.$ ) with linear polarization ( $h$ or $v$ for horizontal or vertical), Equation (8) becomes

$$
\sigma_{0}=\frac{|R(0)|^{2}}{s_{f}^{2}}=\sigma_{0 h h}=\sigma_{0 v v}
$$

where $R(0)$, shorthand for $R_{\eta \eta}(0)$ with $\eta=h$ or $v$, is the Fresnel reflection coefficient for normal incidence, and the NRCS is independent on the polarization state. Applying Equation (9) to Ku band altimeter measurements, a rather peculiar result is discovered $[8-10,13,14]$ : the computed Ku band LPMSS is larger than the total optical MSS in clean water $s_{\infty}^{2}[11,12]$.

The LPMSS $s_{f}^{2}$ is an integrated surface wave property, which is defined as

$$
s_{f}^{2}=\int_{0}^{k_{u}} k^{2} S(k) d k
$$

where $S$ is the surface wave elevation spectrum, $k$ is surface wavenumber, and $k_{u}$ is the upper limit of lowpass filter, which is in turn proportional to the EM wavenumber $k_{r}$. The ratio $k_{r} / k_{u}$ is generally given as between 3 and $6[9,10]$. When distinction of EM frequency is desired, $s_{f}^{2}$ is also given as $s_{k u}^{2}$ in this paper. For example, for Ku band EM frequency $f_{r}=14 \mathrm{GHz}$ and $k_{u}=k_{r} / 3=293 / 3=98 \mathrm{rad} / \mathrm{m}$, the corresponding $s_{f}^{2}$ is $s_{98}^{2}$ for clarification. The optical EM frequency is many orders of magnitude higher than those of the microwave sensors used in ocean remote sensing, so $s_{\infty}^{2}$ is expected to be the upper bound of $s_{f}^{2}$ observed by microwave equipment.

Figure 2a shows the Ku band altimeter NRCS with collocated buoy winds in the Gulf of Alaska and Bering Sea [14], and the calculated NRCSs based on the optical MSS from sun glitter analyses in clean and slick waters with wind speed measured onboard a research vessel in the region [11] or collocated spaceborne scatterometer wind product [12]. Figure $2 \mathrm{~b}$ shows the optical MSS and $s_{f}^{2}$ derived from the Ku band altimeter NRCS using Equation (9). Two sets of MSS reported in Cox and Munk (C54) are also from sun glitter analysis but from a spaceborne optical sensor (wind speed up to $15 \mathrm{~m} / \mathrm{s}$ ); the results are essentially identical to those of the clean water condition in Cox and Munk [11]. For the slick waters, surface waves shorter than about $30 \mathrm{~cm}$, corresponding to $k_{u}=21 \mathrm{rad} / \mathrm{m}$, are suppressed [11]; therefore, the two sets of optical MSS are $s_{\infty}^{2}$ and $s_{21}^{2}$. The Ku band (14 GHz) EM wavelength is about $2.1 \mathrm{~cm}$, with the factor $k_{r} / k_{u}=3$ to 6 applied, the observed LPMSS is between $s_{98}^{2}$ and $s_{49}^{2}$. The surface roughness sensed by the Ku band altimeter is expected to be between the optical data in clean and slick waters. This, however, is not the case for the result in low and moderate winds $\left(U_{10} \leq \sim 10 \mathrm{~m} / \mathrm{s}\right)$, as illustrated in Figure $2 \mathrm{~b}$. Especially intriguing is that the discrepancy increases toward lower wind condition for which the ocean surface is less nonlinear and simplifications made in the EM theoretical development are better justified. 

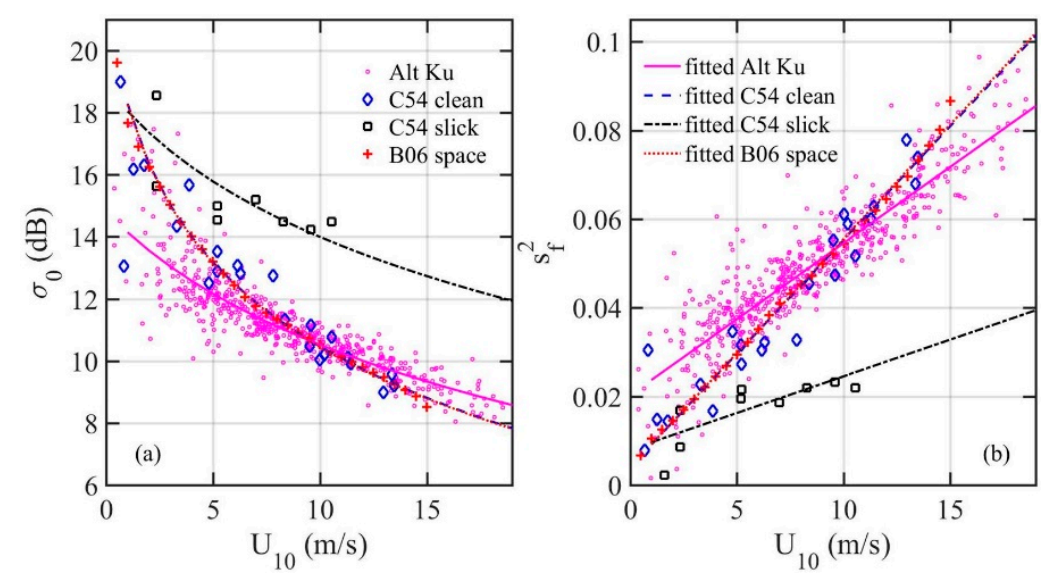

Figure 2. (a) Ku band altimeter NRCS and comparison with computational results using Equation (9) with the optical MSS in clean and slick waters: C54 and B06. (b) The MSS computed using Equation (9) with the Ku band altimeter NRCS and comparison with the optical MSS in clean and slick waters. The smooth curves are linear fitting to the three sets of MSS data. The smooth curves in (a) are the NRCS computation using Equation (9) with the linear fitted curves of the MSS data.

As mentioned in the Introduction, many researchers resort to using an effective reflectivity much smaller than that computed from the relative permittivity [8-10]; more discussion on reflectivity is deferred to Section 4.2. In Hwang et al. [13,14], the authors stress that Equation (8) carries the physical meaning of an exponentially attenuating contribution with respect to the incidence angle $\theta_{i}$. Borrowing the two-scale concept of scattering at moderate incidence angles [8] that the local incidence angle can be modified by the background waves, and reexamining Equation (6), the left-hand side of Equation (6) can be written as $\sigma_{0 \xi \eta}\left(\theta_{s}, \gamma\right)$, and Equation (8) is explicitly written as

$$
\sigma_{0 \xi \eta}\left(\theta_{s}=\theta_{i}, \gamma\right)=\left|R_{\xi \eta}(\iota)\right|^{2} \frac{\sec ^{4} \gamma}{s_{f}^{2}} \exp \left(\frac{-\tan ^{2} \gamma}{s_{f}^{2}}\right)
$$

The alternative explanation offered in $[13,14]$ is that Equation (8) can be interpreted as the specular scattering pattern with respect to the incidence angle $\theta_{i}$. This is illustrated in a conceptual sketch (Figure 7, [13]), which is reproduced as Figure 3 here. In the Figure 7 of Ref [13], the parallel horizontal lines represent the far-field EM wave fronts emitted from zenith and impinge on the ocean surface. Five scattering patterns are illustrated. Patterns 1,4 , and 5 are from three incrementally rougher patches located on background surfaces that are locally parallel to the incoming wave fronts such that the local incidence angle is not changed from the nominal incidence angle ( 0 in this case). The backscattering returns from the three patches are inversely proportional to the surface roughness as expected from Equation (9). Patterns 2, 3, and 4 are from three statistically identical roughness patches and located on background surfaces with different orientations. The backscattering strengths from the three patches observed by the antenna at zenith are different, although the reflecting patches have identical statistical roughness. The difference of the returns toward the nominal incidence direction (from zenith) reflects the tilting effect as described by the exponential term in Equation (8) or Equation (11). 


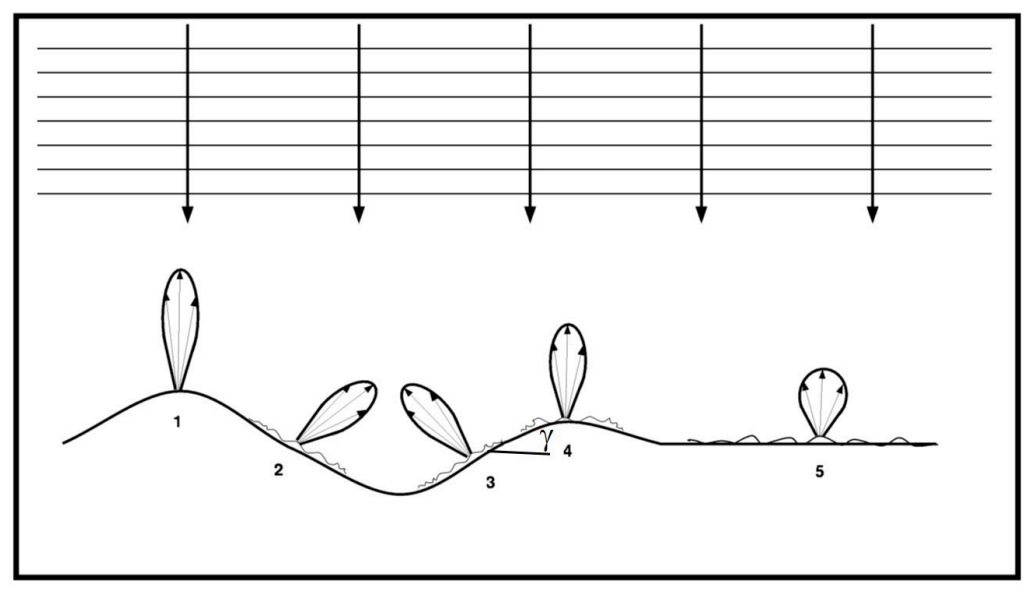

Figure 3. A conceptual sketch depicting the scattering of radar waves by surface patches of various roughness $(1,4$, and 5$)$ and the effect of tilting background surface on the backscattering intensity from patches of identical statistical roughness (2, 3, and 4); reproducing (Figure 7, [13]).

Consequently, there is one more step to obtaining the backscattering NRCS accounting for modification of local incidence angle, that is,

$$
\begin{array}{r}
\sigma_{0 \xi \eta}\left(\theta_{s}=\theta_{i}\right)=\int_{-\infty}^{\infty} \int_{-\infty}^{\infty}\left|R_{\xi \eta}(\iota)\right|^{2} \frac{\sec ^{4} \theta_{i l}}{s_{f}^{2}} \exp \left(\frac{-\tan ^{2} \theta_{i l}}{s_{f}^{2}}\right) . \\
p\left(\tan \gamma_{x}, \tan \gamma_{y}\right) d \tan \gamma_{x} d \tan \gamma_{y}
\end{array}
$$

where $\theta_{i l}$ is the local incidence angle satisfying the specular reflection condition (i.e., $\theta_{i l}=\theta_{s l}$ on the tilting surface, $\theta_{s l}$ is the local scattering angle $), \gamma$ is the global tilting angle, $\tan \gamma=\left(\tan \gamma_{x}\right.$, $\left.\tan \gamma_{y}\right)=\left(\zeta_{x}, \zeta_{y}\right)$ is the corresponding surface slope, and $p\left(\tan \gamma_{x}, \tan \gamma_{y}\right)=p\left(\zeta_{x}, \zeta_{y}\right)$ is the probability density function (pdf) of the background (global) surfaces that tilt the specular patches. The term inside the double integrals and before the pdf function, that is essentially Equation (8), is now interpreted as the scattering pattern, and Equation (12) is equivalent to the tilting modulation of local incidence angle in the discussion of scatterometer returns [8] with the pdf function accounting for the off-specular contribution. For the Gaussian distribution of sea surface slopes with equal up-downwind and crosswind slope components, i.e., $s_{f x}^{2}=s_{f y}^{2}=s_{f}^{2} / 2$,

$$
p\left(\tan \gamma_{x}, \tan \gamma_{y}\right)=\frac{1}{\pi s_{f}^{2}} \exp \left(\frac{-\tan ^{2} \gamma}{s_{f}^{2}}\right)
$$

For the altimeter application, we have

$$
\begin{array}{r}
\sigma_{0}(0)=\int_{-\infty}^{\infty} \int_{-\infty}^{\infty}|R(0)|^{2} \frac{\sec ^{4} \gamma}{s_{f}^{2}} \exp \left(\frac{-\tan ^{2} \gamma}{s_{f}^{2}}\right) \\
\frac{1}{\pi s_{f}^{2}} \exp \left(\frac{-\tan ^{2} \gamma}{s_{f}^{2}}\right) d \tan \gamma_{x} d \tan \gamma_{y}
\end{array}
$$

Figure 4a shows the NRCS results computed with Equation (14) and their comparison with altimeter observations. For reference, the results computed with Equation (9) are also shown. Figure $4 \mathrm{~b}$ shows the two sets of $s_{f}^{2}$ used in the computation. They are based on the H18 spectrum model $\left(s_{H 18}^{2}\right)[17,27]$ integrated to $k_{u}=k_{r} / 3$ and $k_{r} / 5$. The agreement between measurement and theoretical computation using Equation (14) with H18 MSS integrated to $k_{u}=k_{r} / 3$ is improved considerably. More discussion on LPMSS analysis and reflectivity $|R(0)|^{2}$ is deferred to Section 4 . 

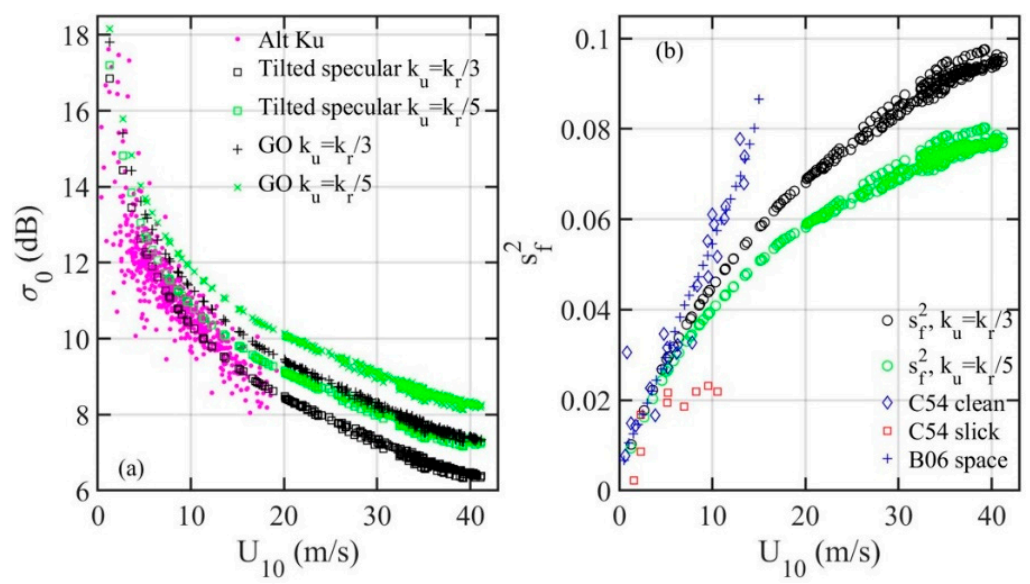

Figure 4. (a) Ku band NRCS and comparison with model computation with Equation (14), for comparison; computation results with Equation (9) are also shown (labeled GO). (b) The LPMSS used for the NRCS computation shown in (a), and comparison with the optical MSS in clean and slick waters. The LPMSS is computed with the H18 spectrum model integrated to $k_{r} / 3$ and $k_{r} / 5$.

For specular returns, the wind direction enters into the mean square slopes in the up-downwind and crosswind components. The ratio of the crosswind to up-downwind components is close to one based on Cox and Munk's optical sun glitter data [11], and our analysis assumes equal up-downwind and crosswind slope components. More discussion on the up-downwind and crosswind surface roughness components is also given in Section 4 of [17], see their Figure 10 and related discussion.

\subsection{Band CYGNSS Analysis}

Tilting modification is expected to impact specular reflections at oblique angles. Applying the same procedure discussed in the altimeter case to Equation (6) for $\sigma_{0 \xi \eta}\left(\theta_{s}, \gamma\right)$, the NRCS for 2D Gaussian pdf of tilting surfaces is:

$$
\begin{array}{r}
\sigma_{0}\left(\theta_{s}\right)=\int_{-\infty}^{\infty} \int_{-\infty}^{\infty}\left|R_{\xi \eta}(\iota)\right|^{2} \frac{\sec ^{4} \gamma}{s_{f}^{2}} \exp \left(\frac{-\tan ^{2} \gamma}{s_{f}^{2}}\right) \\
\frac{1}{\pi s_{f}^{2}} \exp \left(\frac{-\tan ^{2} \gamma}{s_{f}^{2}}\right) d \tan \gamma_{x} d \tan \gamma_{y}
\end{array}
$$

It turns out that for global positioning system reflectometry (GPSR) with right-handcircular transmit and left-hand-circular receive, the $\left|R_{l r}(\iota)\right|^{2}$ is almost independent on local incidence angle, $\iota$, up to about $50^{\circ}[27]$, so $\left|R_{l r}(\iota)\right|^{2}$ plays a rather minor role in computing circular polarization NRCS except at low grazing angles. The reflectivity in Equation (6) or Equation (15) can be approximated by $\left|R_{l r}(0)\right|^{2}$ for GPSR from the ocean surface.

Through GPSR delay Doppler waveform analyses, there are now several sets of L band LPMSS collected in TC conditions [18-21]. These data are identified as $s_{G P S R}^{2}$ and illustrated in Figure 5 (labeled K0913 and G1318 in the legend); the least-squares fitted curve is given by the solid black line (labeled GPSR). The $s_{G P S R}^{2}$ data have served to address one of the most unsettled issues in the ocean surface wind wave spectrum function $S(f)$, i.e., the spectral slope in the high frequency region $[17,28]$. The clarification of spectral slope is especially critical to the LPMSS determination using an ocean wave spectrum model. The refinement of the $S(f)$ function, in turn, offers the feasibility to derive LPMSS given $U_{10}$ and windsea dominant wave period $T_{p}$ from operational-system measurements [29] or to create synthetic high-wind LPMSS data set with a small number of critical tropical cyclone (TC) parameters $[17,27]$. Also shown in Figure 6 are the LPMSS computed from the G18 $\left(s_{G 18}^{2}\right)$ and H18 $\left(s_{H 18}^{2}\right)$ spectrum models $[17,27]$ with $k_{u}=k_{r} / 3$ and $k_{r} / 5$. In addition, the results based on E97 $\left(s_{E 97}^{2}\right)$ [30] are also displayed; the E97 is used in the CYGNSS project $[31,32]$. For comparison, the optical data obtained in clean and slick 
sea surfaces [11,12] are illustrated with black markers in the Figure. The GPSR data have expanded the wind speed coverage considerably (from 15 to $59 \mathrm{~m} / \mathrm{s}$ ), and they are critical for refining the ocean surface wind wave spectrum models in high wind conditions. More detail on deriving LPMSS from a wave spectrum is deferred to Section 4.1.

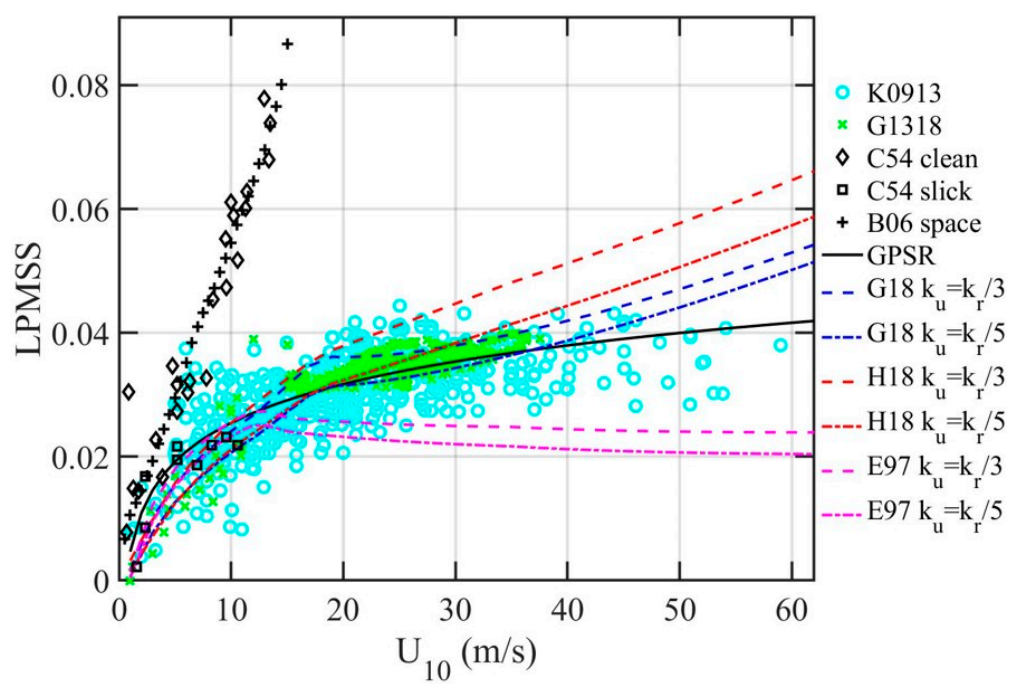

Figure 5. L band LPMSS derived from GPSR delay Doppler analyses (labeled K0913 and G1318), the least-squares curve fitted through all the GPSR data is given by the solid black line (labeled GPSR). Three sets of computation from spectrum models (E97, G18, and H18) with $k_{u}=k_{r} / 3$ and $k_{r} / 5$ are also illustrated. For comparison, optical MSS in clean and slick waters is shown with black markers.

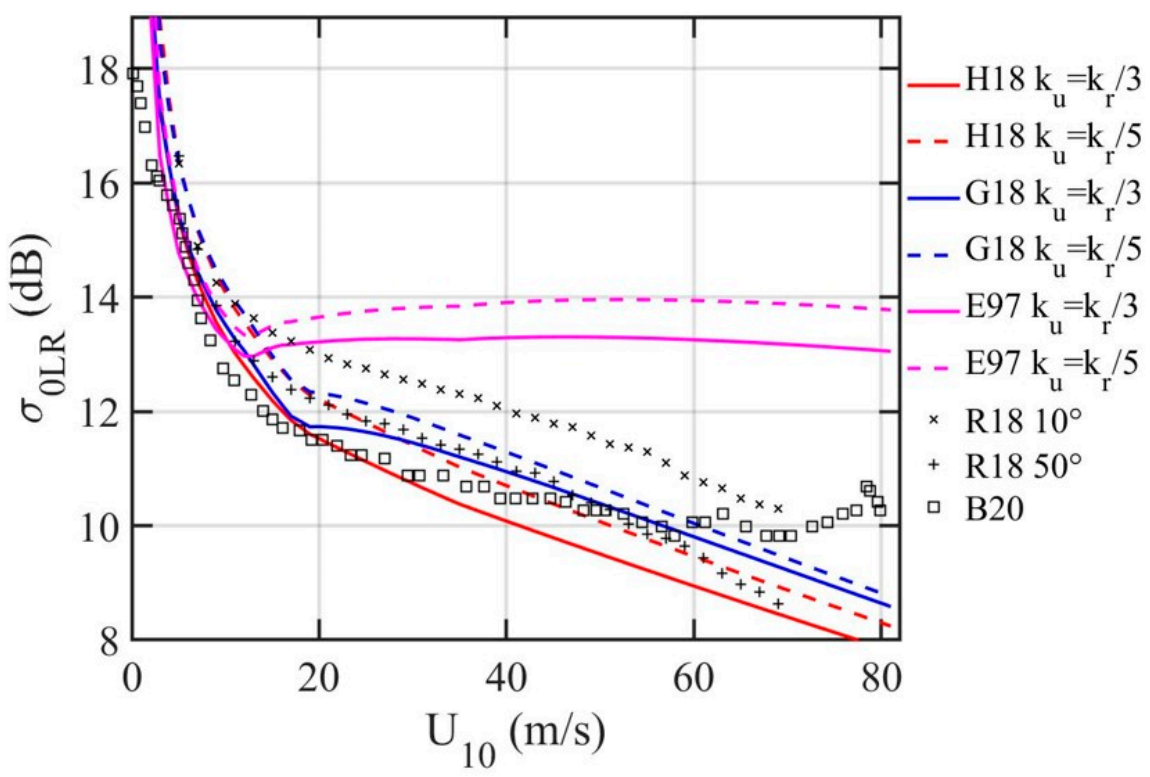

Figure 6. NRCS computed with LPMSSs derived from E97, G18, and H18 spectrum models, and comparison with the CYGNSS NRCS observations: R18 and B20.

Retrieving NRCS from GPSR, or global navigation satellite system reflectometry (GNSSR) in general, remains a challenging task [22-24]. Here we investigate the properties of L-band NRCS through forward computation using Equation (15). The results are then compared with the most recent publications of L band NRCS results from the CYGNSS mission $[23,24]$. Figure 6 shows the results computed with Equation (15) and the LPMSS derived from the three spectrum models shown in Figure 5. Superimposed with the computation curves are two sets of CYGNSS data: the black crosses and pluses labeled 
R18 [23] are the GMF at $10^{\circ}$ and 50 ${ }^{\circ}$, and the black squares labeled B20 [24] are the incidenceangle-averaged result. It is clear that the CYGNSS GMF is still evolving. Interestingly, there is a good agreement between the most recent version [24] (B20: black squares) and the computed NRCS with $s_{G 18}^{2}$ and $s_{H 18}^{2}$ integrated to $k_{u}=k_{r} / 3$; the model-data difference is less than about $1 \mathrm{~dB}$ to wind speed up to about $60 \mathrm{~m} / \mathrm{s}$. The computed NRCS with $s_{E 97}^{2}$ is also in good agreement with data for low to moderately high winds $\left(U_{10} \leq \sim 14 \mathrm{~m} / \mathrm{s}\right)$ but fares far worse in higher winds, because E97 underestimates the LPMSS for $U_{10}$ greater than about $14 \mathrm{~m} / \mathrm{s}$ (Figure 5). It illustrates the importance of choosing an accurate surface wave spectrum model for ocean remote sensing analysis. More discussion on LPMSS and reflectivity $\left|R_{\zeta \eta}(\iota)\right|^{2}$ is deferred to Section 4 .

\section{Discussion}

\subsection{LPMSS, Wind Speed, and Wave Development Stage}

The functional form of the ocean surface wind wave spectrum remains one of the most uncertain quantities in ocean remote sensing problems. For specular return, the relevant property is the LPMSS with the upper integration wavenumber $k_{u}$ determined by the EM wavenumber $k_{r}$. From altimeter analyses $[9,10]$ the range of $k_{r} / k_{u}$ is generally determined to be between 3 and 6 . In this paper, we have shown results of specular computation obtained with $k_{r} / k_{u}=3$ and 5, which corresponds to $k_{u}=11$ and $6.6 \mathrm{rad} / \mathrm{m}$ for L band $(1.575 \mathrm{GHz})$, and 98 and $59 \mathrm{rad} / \mathrm{m}$ for $\mathrm{Ku}$ band $(14 \mathrm{GHz})$. The contribution of long surface waves in the energetic dominant wave region becomes more important as wind speed increases and EM frequency decreases.

The value of the wave spectral slope $-s$ in the high frequency region of the wind wave frequency spectral function is one of the most uncertain spectral properties critical to the determination of LPMSS. Traditional wind wave spectrum models assume $s$ to be either 4 or 5 [33-36], although field observations have shown a wide range between about 2 and $7[17,28]$. The wave height spectral level drops sharply toward both high and low frequencies from the spectral peak; therefore, wave height measurements are not very sensitive for addressing the spectral slope issue. Wave slope data are much more useful for this task $[27,29]$.

For many decades, the airborne sun glitter analyses in clean and slick waters reported in 1954 [11] have remained the most comprehensive ocean surface MSS dataset; the wind speed range is between 0.7 and $13.5 \mathrm{~m} / \mathrm{s}$ for the clean water condition, and between 1.6 and $10.6 \mathrm{~m} / \mathrm{s}$ for the slick water condition. The spaceborne sun glitter analysis reported in 2006 [12] expands slightly the wind speed range of clean water condition to about $15 \mathrm{~m} / \mathrm{s}$, and the results are essentially identical to those of the clean water condition reported in 1954 [11]. The recent results of $s_{G P S R}^{2}$ further extend the LPMSS wind speed coverage to $59 \mathrm{~m} / \mathrm{s}$ [18-21]. With the EM frequency of $1.575 \mathrm{GHz}$, the $k_{u}$ is between about 5 and $11 \mathrm{rad} / \mathrm{m}$, and $s_{G P S R}^{2}$ data are most useful for investigating the wind wave spectrum slope. The study leads to establishing a general wind wave spectrum function G18 [17], with the applicable upper limit $\left(k_{\max }\right)$ of the G18 spectrum function estimated to be about the upper range of $\mathrm{L}$ band $k_{u}(11 \mathrm{rad} / \mathrm{m})$. For $\mathrm{Ku}$ band application, the hybrid model $\mathrm{H} 18$ is more suitable. The H18 model uses G18 for long waves and H15 [16] for short waves, with linear interpolation between $k=1$ and $4 \mathrm{rad} / \mathrm{m}$ [27].

Wind speed $U_{10}$ and windsea dominant wave period $T_{p}$ are the only required input for computing the G18 and H18 spectrum (and many other spectrum models such as the E97 discussed in Section 3). The combination of $U_{10}$ and $T_{p}$ can be expressed as the dimensionless spectral peak frequency $\omega_{\#}=U_{10} / c_{p}=U_{10} /\left(g T_{p} / 2 \pi\right)$, where $c_{p}$ is the wave phase speed of the spectral peak component, and $g$ is gravitational acceleration. The inverse of $\omega_{\#}$ is wave age, which represents the stage of wave development. Determining the wave spectrum requires consideration of both wind speed and wave development stage. With a wave spectrum function, the $s_{k u}^{2}$ can be pre-calculated for a range of $U_{10}, \omega_{\#}$, and $k_{u}$. For example, Figure 7a,b show the contour maps of H18 $s_{98}^{2}$ and $s_{11}^{2}$, respectively. They are illustrated for $U_{10}$ between 0 and $70 \mathrm{~m} / \mathrm{s}$, and $\omega_{\#}$ between 0.8 and 5.2. These pre-calculated 
results serve as design curves or lookup tables for quickly obtaining the desired $s_{f}^{2}$ through interpolation. Superimposed in the Figures are the observed $\omega_{\#}\left(U_{10}\right)$ in TC and non-TC conditions. Because the wave age $1 / \omega_{\#}$ is defined as the ratio of dominant wave phase speed $c_{p}$ and wind speed $U_{10}, U_{10}$, and $\omega_{\#}=U_{10} / c_{p}$ are not independent variables. The observed $\omega_{\#}\left(U_{10}\right)$ in TC and non-TC conditions show the general linear relationship with a narrow range of $\omega_{\#}$ variation for a particular wind speed $U_{10}$ as illustrated by the color markers in Figure $7 \mathrm{a}, \mathrm{b}$.
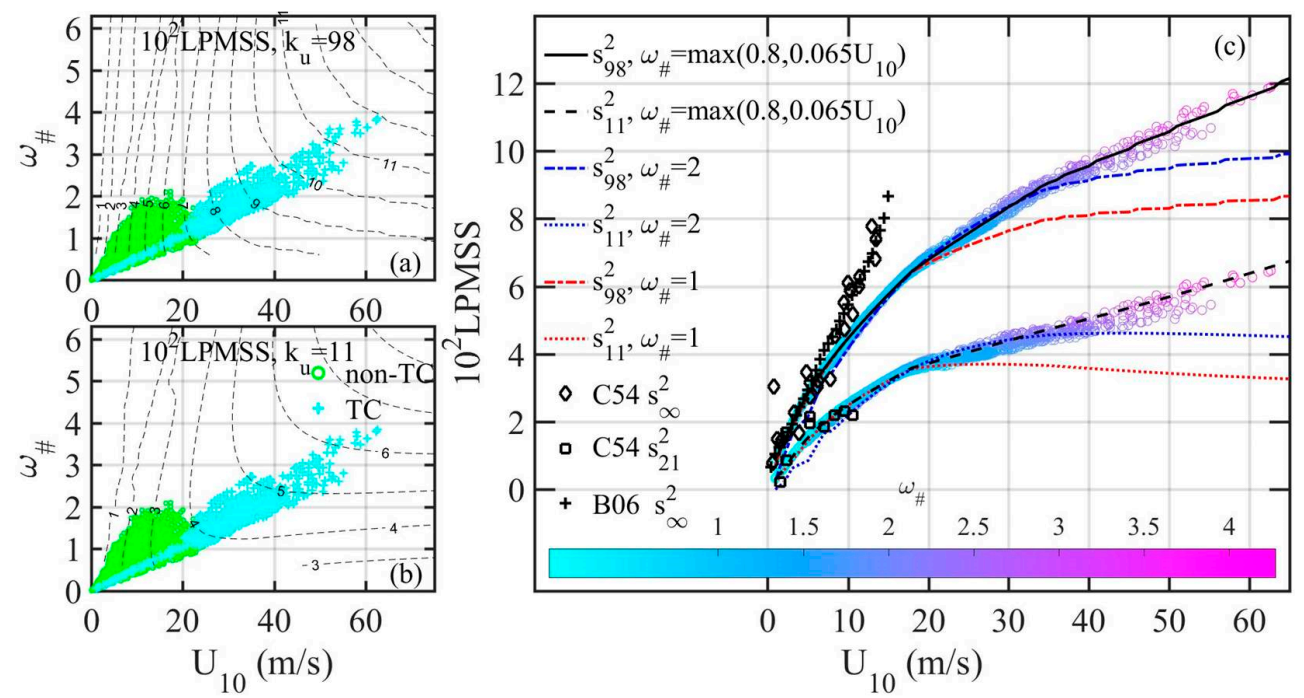

Figure 7. Pre-calculated H18 LPMSS contour maps for (a) $k_{u}=98 \mathrm{rad} / \mathrm{m}$ and (b) $k_{u}=11 \mathrm{rad} / \mathrm{m}$. Superimposed in the Figures are the observed $\omega_{\#}\left(U_{10}\right)$ in TC and non-TC conditions. (c) Color markers show the interpolated LPMSS for $k_{u}=98$ and $11 \mathrm{rad} / \mathrm{m}$ (upper and lower sets, respectively) using the observed $\omega_{\#}\left(U_{10}\right)$ in TC and non-TC conditions. For comparison, illustrated with black markers are the optically sensed MSS in clean and slick waters. Also shown in the Figure are the interpolated LPMSS assuming constant $\omega_{\#}$ (1 and 2), and $\omega_{\#}$ approximated by Equation (16).

The interpolated $\mathrm{H} 18 s_{98}^{2}$ and $s_{11}^{2}$ are presented with color markers in Figure 8. For comparison, the optically sensed $s_{\infty}^{2}$ in clean water [11,12] and $s_{21}^{2}$ in slick water [11] are illustrated with black markers in the Figure. Also shown in Figure 8 are the interpolated $\mathrm{H} 18 s_{98}^{2}$ and $s_{11}^{2}$ assuming constant $\omega_{\#}$ (1 and 2 are used for illustration). As wind speed increases, the difference increases between $s_{f}^{2}$ computed with constant and observed $\omega_{\#}$. Interestingly, if the approximation

$$
\omega_{\#}=\max \left(0.8,0.065 U_{10}\right)
$$

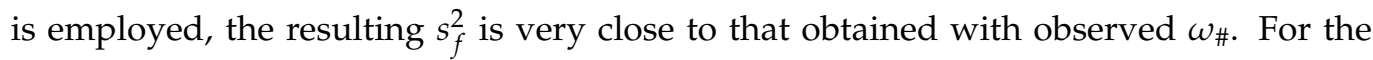
purpose of obtaining $s_{f}^{2}$ from a wave spectrum function, approximation Equation (16) simplifies the procedure in practical applications, since it requires only the $U_{10}$ input (with $k_{u}$ specified). 


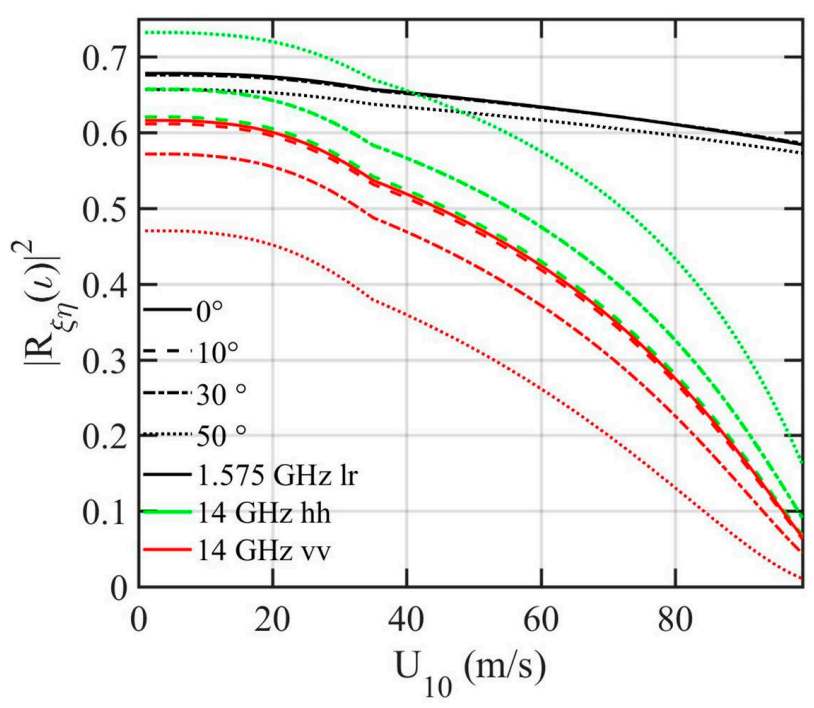

Figure 8. The sea surface reflectivity at $0^{\circ}, 10^{\circ}, 30^{\circ}$, and $50^{\circ}$ incidence angles (solid, dashed, dasheddotted, and dotted curves, respectively) for $\mathrm{Ku}(14 \mathrm{GHz}$, green and red curves) and $\mathrm{L}(1.575 \mathrm{GHz}$, black curves) bands. The GPSR signals are right-hand-circular transmit and left-hand-circular receive, so for $\mathrm{L}$ band $\left|R_{l r}(l)\right|^{2}$ is given (black curves). For Ku band, the reflectivity for $h h$ and $v v$ polarizations is shown (green and red, respectively).

\subsection{Surface Reflectivity Considering Wave Breaking}

The reflectivity $\left|R_{\tilde{\eta}}(\iota)\right|^{2}$ is a function of relative permittivity and generally treated as a constant for a given EM frequency (with the assumption of some representative sea surface temperature and sea surface salinity: $293 \mathrm{~K}$ and $35 \mathrm{psu}$ are used throughout this paper; the relative permittivity of sea water is computed with the formula given by Klein and Swift [37]). In high winds when air is entrained by wave breaking into the water surface layer and foam covers the water surface, the modification of relative permittivity by the mixed air needs to be considered. Figure 8 shows the Fresnel reflectivity at $0^{\circ}$, $10^{\circ}, 30^{\circ}$, and $50^{\circ}$ incidence angles for $\mathrm{Ku}(14 \mathrm{GHz})$ and $\mathrm{L}(1.575 \mathrm{GHz})$ frequencies. The $\mathrm{Ku}$ band altimeters discussed in this paper operate with linear polarizations ( $h$ and $v$ ), so $\left|R_{h h}(\theta)\right|^{2}$ and $\left|R_{v v}(\theta)\right|^{2}$ are illustrated. The GPSR signals are right-hand-circular transmit and left-hand-circular receive, so for L band $\left|R_{l r}(l)\right|^{2}$ is given; its dependence on incidence angle is very weak up to about $50^{\circ}$ incidence angle [27]. For altimeter reflection from the ocean surface, $\left|R_{\xi \eta}(0)\right|^{2}$ is the quantity of interest (Section 3.2), and it is independent of polarization states $h h, v v$, and $l r$, but can vary considerably with wind speed as a result of air entrainment by wave breaking. The foam modification is more severe toward higher frequency as expected; this can be seen from comparing the black solid line of $\mathrm{L}$ band and $\mathrm{red} /$ green (overlapped) solid lines of $\mathrm{Ku}$ band. The procedure to account for the foam effect is briefly described below.

Through analyses of microwave radiometer measurements collected in TCs that cover a wide range of frequencies, incidence angles, and both horizontal and vertical polarizations [38-46], the effects of surface foam generated by wave breaking are expressed as a function of wind speed, microwave frequency, and incidence angle $[47,48]$. The effective air fraction $F_{a}$ is related to the whitecap coverage $W_{c}$ as described in Appendices $\mathrm{A}$ and $\mathrm{B}$ of [48]. A brief summary is given here. The proposed $F_{a} / W_{c}$ function is

$$
\frac{F_{a}}{W_{c}}=\max \left[1,\left(\frac{f}{f_{r e f}} \cos ^{\alpha} \theta\right)^{\beta}\right]
$$

From empirical fitting the computed brightness temperature with observations [38-46], the following values are recommended for the three parameters in Equation (17):

$$
f_{\text {ref }}=14 \mathrm{GHz} \text {, }
$$


$\alpha=1.3$, and

$$
\beta=\max \left\{0,0.5-\min \left\{0.5,0.5\left[\exp \left(1.1 f / f_{\text {ref }}\right)-1.5\right]\right\}\right\}
$$

The whitecap fraction $W_{c}\left(U_{10}\right)$ is defined by

$$
W_{c}= \begin{cases}0, & u_{*} \leq 0.11 \mathrm{~m} / \mathrm{s} \\ 0.30\left(u_{*}-0.11\right)^{3}, & 0.11<u_{*} \leq 0.40 \mathrm{~m} / \mathrm{s} \\ 0.07 u_{*}^{2.5}, & u_{*}>0.40 \mathrm{~m} / \mathrm{s}\end{cases}
$$

where $u_{*}$ is the wind friction velocity; the drag coefficient connecting $u_{*}$ and $U_{10}$ input $\left(u_{*}=C_{10}^{0.5} U_{10}\right)$ is given by

$$
C_{10}= \begin{cases}10^{-4}\left(-0.0160 U_{10}^{2}+0.967 U_{10}+8.058\right), & U_{10} \leq 35 \mathrm{~m} / \mathrm{s} \\ 2.23 \times 10^{-3}\left(U_{10} / 35\right)^{-1}, & U_{10}>35 \mathrm{~m} / \mathrm{s}\end{cases}
$$

With the effective air fraction $F_{a}$ determined from the whitecap coverage $W_{c}$, the effective relative permittivity $\varepsilon_{e}$ is computed with the refractive mixing rule [49-51]:

$$
\varepsilon_{e}=\left[F_{a} \varepsilon_{a}^{1 / 2}+\left(1-F_{a}\right) \varepsilon_{s w}^{1 / 2}\right]^{2}
$$

where $\varepsilon_{a}$ and $\varepsilon_{s w}$ are the relative permittivities of air and (foamless) sea water, respectively. The effective relative permittivity $\varepsilon_{e}$ is then used to compute the Fresnel reflection coefficient with wind speed dependence as a result of foam effects caused by surface wave breaking.

\subsection{Frequency Dependence and Verification}

With a surface wave spectrum, the LPMSS can be computed for application to any EM frequencies. For example, Figure 9 shows $s_{H 18}^{2}$ integrated to $k_{u}=k_{r} / 3$ (black curves) and $k_{u}=k_{r} / 5$ (red curves) for several microwave frequency bands used frequently in ocean remote sensing ( $\mathrm{L}, \mathrm{C}, \mathrm{X}, \mathrm{Ku}$, and $\mathrm{Ka}$ ) with wind speeds up to $99 \mathrm{~m} / \mathrm{s}$. Also illustrated for comparison is the optical MSS, which is restricted to wind speed below about $15 \mathrm{~m} / \mathrm{s}$. The specular NRCS can be computed with the LPMSS input, as illustrated in Figure 10. For clarity, only results based on $s_{H 18}^{2}$ integrated to $k_{u}=k_{r} / 3$ are shown. It is of interest to verify the model computations with available data.

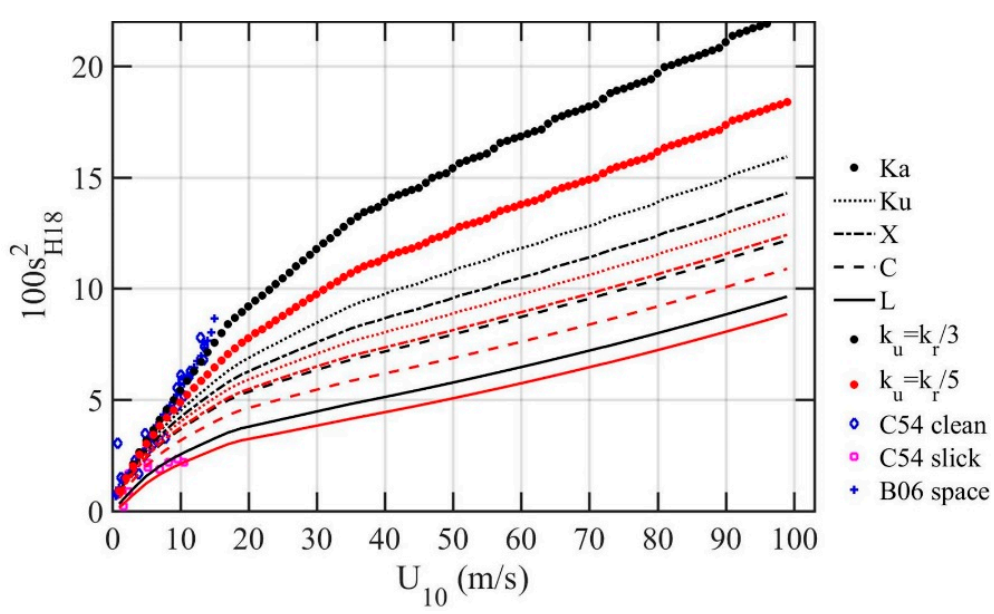

Figure 9. LPMSS for L (1.575 GHz, solid lines), C (6 GHz, dashed), X (10 GHz, dashed-dotted), $\mathrm{Ku}(13.575 \mathrm{GHz}$, dotted), and $\mathrm{Ka}(35.75 \mathrm{GHz}$, dots) bands based on the H18 spectrum (for normal incidence application), black curves are integration to $k_{r} / 3$ and red curves are integration to $k_{r} / 5$. 


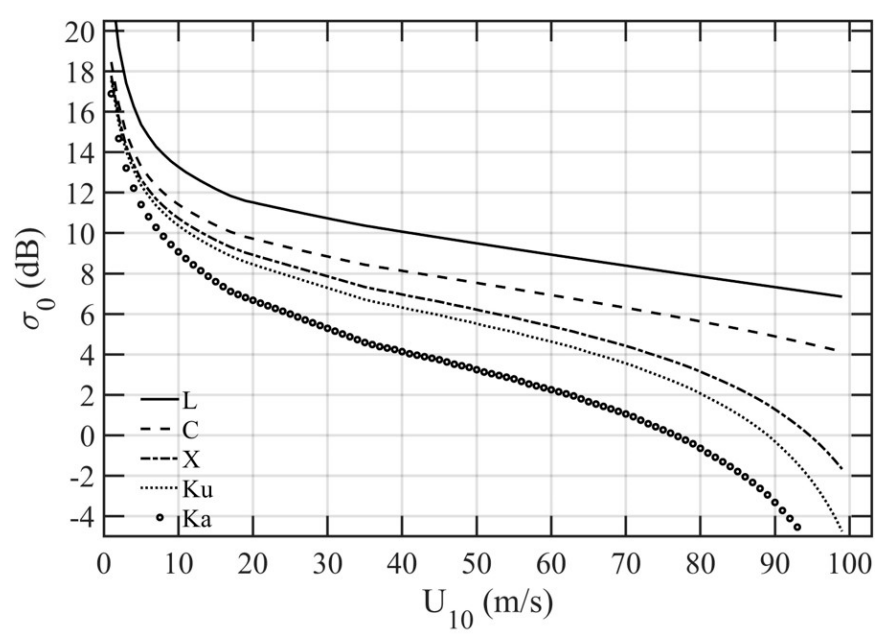

Figure 10. Specular NRCS (normal incidence) dependence on wind speed for L (1.575 GHz), C $(6 \mathrm{GHz}), \mathrm{X}(10 \mathrm{GHz}), \mathrm{Ku}(14 \mathrm{GHz})$, and $\mathrm{Ka}(35.75 \mathrm{GHz})$ bands. All computed with the H18 LPMSS integrated to $k_{r} / 3$.

The Ku band altimeter systems have many more well-calibrated NRCS datasets compared to other frequencies due to the long history of using $\mathrm{Ku}$ band for ocean wind sensing $[9,10,13,14,52-64]$. Three examples are examined here:

1. TOPEX/POSEIDON (T/P) altimeter NRCS (13.575 GHz) and collocated National Oceanographic and Atmospheric Administration (NOAA) National Data Buoy Center (NDBC) buoy datasets in three geographic regions (Gulf of Alaska and Bering Sea, Gulf of Mexico, and Hawaii islands) have been reported in [13,14] with up to seven years of simultaneous measurements and a total of $2174\left(U_{10}, \sigma_{0}\right)$ pairs. The maximum wind speed in the datasets is about $20 \mathrm{~m} / \mathrm{s}$. The maximum temporal and spatial differences between buoy and altimeter data are $0.5 \mathrm{~h}$ and $100 \mathrm{~km}$, respectively. These data are referred to as $\mathrm{H} 02$ from here on.

2. A one-year Tropical Rainfall Mapping Mission (TRMM) Precipitation Radar (TPR, $13.8 \mathrm{GHz})$ dataset [10] with more than $1.13 \times 10^{7}\left(U_{10}, \sigma_{0}\right)$ pairs. The TPR dataset is quite unusual because the wind sensor and altimeter are on the same satellite. The nadir footprint of the TRMM Microwave Imager (TMI) wind sensor is collocated with the footprint of the TPR, and there is no need for temporal interpolation. The spatial resolution of TPR altimeter is about $4.3 \mathrm{~km}$ and that of the TMI is about $25 \mathrm{~km}$, so the spatial separation between TPR, NRCS, and TMI wind speed data is no more than $\pm 12.5 \mathrm{~km}$. The maximum wind speed in the dataset as presented in their Figure 4 is about $29 \mathrm{~m} / \mathrm{s}$. These data are referred to as F03 from here on.

3. An extensive collection of 33 years wind speed, wave height, and altimeter NRCS from 13 satellite missions ranging from Geosat to Sentinel-3A and Jason-3 [64]. The altimeter NRCS is merged with European Centre for Medium-Range Weather Forecasts $(\mathrm{ECMWF})$ model wind speed in $1^{\circ} \times 1^{\circ}$ grids; their Figure 3 shows an example of the Jason-3 (J3) NRCS dependence on wind speed. The maximum wind speed is about $20 \mathrm{~m} / \mathrm{s}$. These data are referred to as R19 from here on.

Figure 11 shows the bin-averaged $\mathrm{Ku}$ band altimeter data from the three examples described above, the data are labeled H02, F03, and R19. The H02 T/P results (red pluses) are processed from our in-house data sets. The R19 J3 results (red circles) are digitized from their Figure 3 [64]. The F03 TPR results (blue diamonds) are digitized from their Figure 4 [10]. Compared to the $\mathrm{T} / \mathrm{P}$ and $\mathrm{J} 3$ results, there is a 1-dB systematic bias in the TPR data, which is subtracted in the Figure. A $1.92 \mathrm{~dB}$ bias is reported [10] from comparing with the modified Chelton and Wentz (MCW) GMF (Table 1, [59]). The MCW is designed for the Geosat altimeter. With improved algorithm and including atmospheric correction, the T/P NRCS differs from the Geosat NRCS by $0.7 \mathrm{~dB}$ [54]. The MCW GMF with $0.7-\mathrm{dB}$ 
adjustment is shown with the red solid line, which goes through the center of $\mathrm{T} / \mathrm{P}, \mathrm{J} 3$, and adjusted TPR data. The blue dashed line is the TPR GMF with $1 \mathrm{~dB}$ adjustment applied. The black line is the model computation with $s_{H 18}^{2}$ integrated to $k_{u}=k_{r} / 3$. The agreement is very good between model computation and all three Ku band data sets. In high winds, the model computation even outperforms the empirically established GMFs. Also shown for reference is the GO solution Equation (9) with the black dashed line, which is about $1 \mathrm{~dB}$ too high compared to the data.

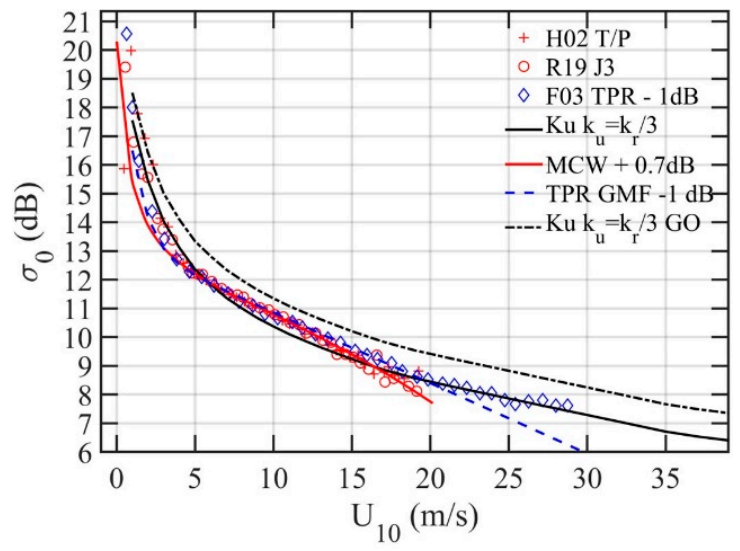

Figure 11. Ku band altimeter NRCS from T/P, J3, and TPR missions (normal incidence) and comparison with NRCS computations using the H18 LPMSS integrated to $k_{r} / 3$ (black solid line). The MCW and TPR GMFs (with adjustment) are shown with red solid and blue dashed lines; more detail is given in the text.

Figure 12 shows the data from all three EM frequencies together and the comparison with model computation using (14) with $s_{H 18}^{2}$ integrated to $k_{u}=k_{r} / 3$. The number of reported data sets is considerably less in other EM frequencies. As mentioned in Section 3, there are two L band NRCS data sets reported from the CYGNSS mission [23,24]. A couple of Ka band altimeter (ALtiKa) data sets have also been reported from the SARAL mission $[25,26]$. For the Ka band, the model-data agreement (red markers and solid line) is close to that of the $\mathrm{Ku}$ band comparison (black markers and solid line). For L band, the model results with $s_{H 18}^{2}$ integrated to $k_{u}=k_{r} / 3$ are shown (magenta marker and solid line). Less than $1 \mathrm{~dB}$ difference is found between model and measurements to wind speed about $60 \mathrm{~m} / \mathrm{s}$. Also shown for reference are the GO solutions Equation (9) for the three frequencies illustrated with dashed lines, which are about $1 \mathrm{~dB}$ too high compared to the data.

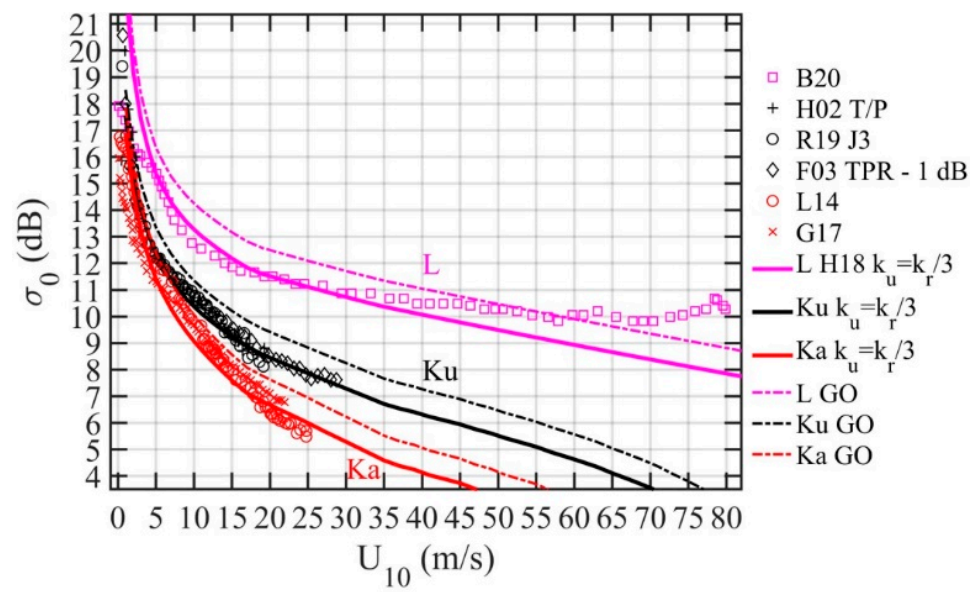

Figure 12. Model-measurement comparison for $\mathrm{L}, \mathrm{Ku}$, and $\mathrm{Ka}$ microwave frequencies; more detail is given in the text. 


\subsection{Incidence and Scattering Angle Dependence}

The NRCS dependence on the incidence and scattering angles hinges on $\iota$ and $\gamma$ as prescribed by Equation (3) and Equation (7). Figure 13a,b show examples of in-plane $\left(\phi_{s}=0^{\circ}\right) v v$ and $h h$ scattering of $\mathrm{Ku}$ band (EM frequency $f$ is $14 \mathrm{GHz}$ ) at $5 \mathrm{~m} / \mathrm{s}$ wind speed. For clarity, the contour lines are $2 \mathrm{~dB}$ apart for NRCS greater than $5 \mathrm{~dB}, 5 \mathrm{~dB}$ apart between -30 and $5 \mathrm{~dB}$, and $10 \mathrm{~dB}$ apart for NRCS less than $-30 \mathrm{~dB}$. The NRCS contours are symmetric to the $\theta_{i}=\theta_{s}$ line. This is a consequence of reciprocity, since we get the same set of $(l, \gamma)$ from Equation (3) and Equation (7) when $\theta_{i}$ and $\theta_{s}$ are swapped. The dropoff along the $\theta_{i}=\theta_{s}$ line is relatively mild: about $2.1 \mathrm{~dB}$ between $\theta_{i}=\theta_{s}=0^{\circ}$ and $\theta_{i}=\theta_{s}=60^{\circ}$. The NRCS dropoff with respect to $\Delta \theta=\theta_{i}-\theta_{s}$ is dependent on incidence angle. For example, with $\theta_{i}=0^{\circ}$, the NRCS difference is about $4 \mathrm{~dB}$ for $\theta_{s}$ from $0^{\circ}$ to $20^{\circ}$, and much steeper at large $\theta_{s}$, about $14 \mathrm{~dB}$ for the same $\Delta \theta$ with $\theta_{s}$ from $20^{\circ}$ to $40^{\circ}$. Figure $13 \mathrm{c}$, d show variation of $v v$ and $h h$ NRCS along $\theta_{i}=\theta_{s}$ for scattering azimuth angles $\phi_{s}=0^{\circ}, 45^{\circ}, 90^{\circ}, 135^{\circ}$, and $180^{\circ}$. Interestingly, in the in-plane condition $\left(\phi_{s}=0^{\circ}\right.$, solid black lines in Figure $\left.13 \mathrm{c}, \mathrm{d}\right)$, the SPT predicts strong NRCS even at low grazing angles. For this configuration $\left(\theta_{i}=\theta_{S}\right.$, $\left.\phi_{s}=0^{\circ}\right), \gamma=0^{\circ}, \iota=\theta_{i}=\theta_{s}$ (Figure 14a), the in-plane specular forward scattering is just like altimeter that reflects from flat facets $\left(\gamma=0^{\circ}\right)$, except that now the effective incidence angle is $\iota=\theta_{i}=\theta_{s}$, and the NRCS is $\sigma_{0 \xi \eta}=\left|R_{\tilde{\xi} \eta}(\iota)\right|^{2} / s_{f}^{2}$. For the same ocean surface roughness, it varies only with the surface reflectivity (Figure 14b). Bistatic radars have been used in establishing forward-scatter fences for air and sea craft detection based on the strong forward scattering principle [65-69]. In the out-of-plane conditions $\left(\phi_{s} \neq 0^{\circ}\right)$, the dropoff toward grazing is rather rapid at large $\theta_{i}=\theta_{s}$. More discussion on the dependence on scattering azimuth angle is given later.
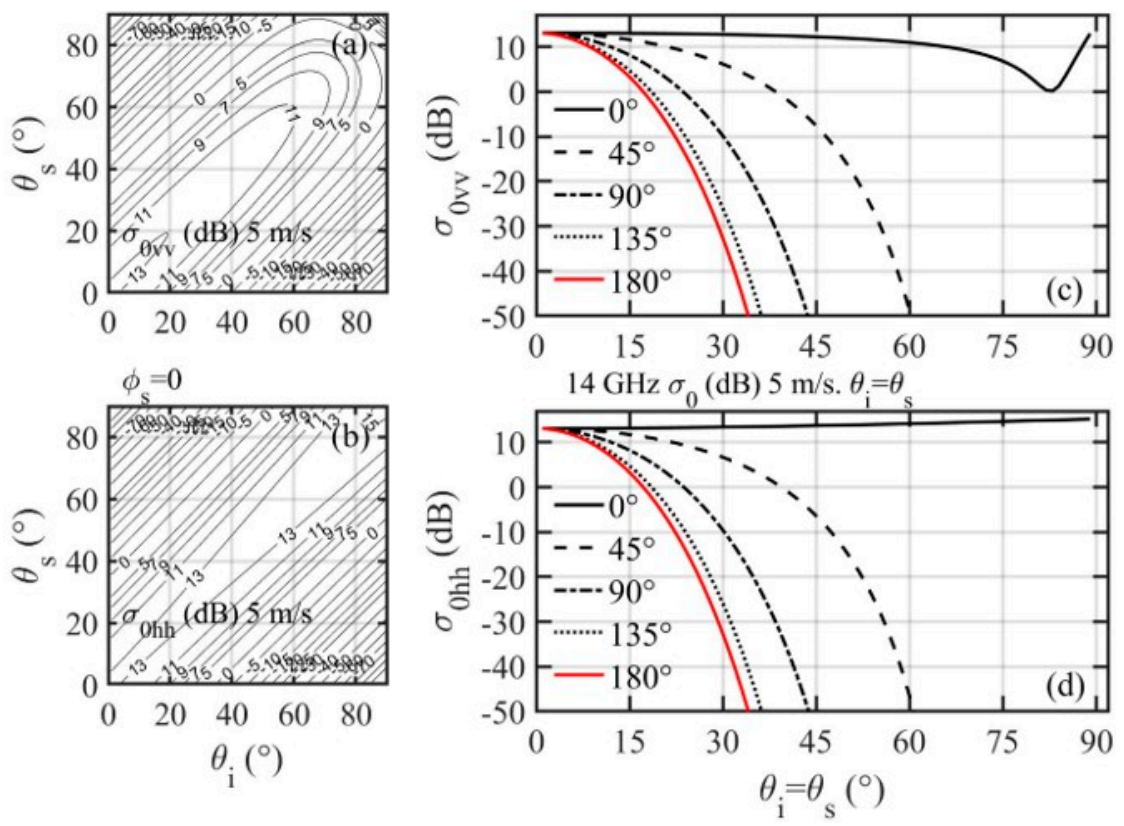

Figure 13. Examples of NRCS dependence on incidence and scattering angles. In-plane forward scattering $\left(\phi_{S}=0^{\circ}\right)$ : (a) $v v,(\mathbf{b}) h h$. Variation of NRCS along $\theta_{i}=\theta_{S}$ for $\phi_{S}=0^{\circ}, 45^{\circ}, 90^{\circ}, 135^{\circ}$, and $180^{\circ}$ scattering azimuth angles: (c) $v v,(\mathbf{d}) h \mathrm{~h}$. The microwave frequency is $14 \mathrm{G} \mathrm{Hz}$ and wind speed is $5 \mathrm{~m} / \mathrm{s}$. 

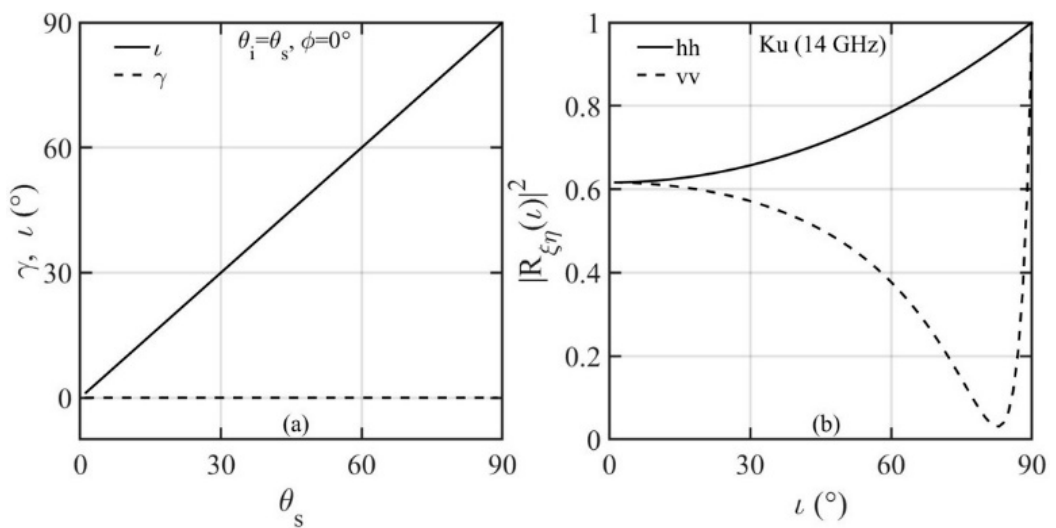

Figure 14. Relevant parameters governing in-plane specular reflection $\left(\theta_{i}=\theta_{s}, \phi_{s}=0^{\circ}\right)$ : (a) local incidence angle $\iota$ and facet angle $\gamma,(\mathbf{b})$ surface reflectivity.

Figure 15a shows the in-plane $\left(\phi_{s}=0^{\circ}\right)$ NRCS dependence on $\theta_{s}$ for $\theta_{i}=50^{\circ}, U_{10}=5$, and $15 \mathrm{~m} / \mathrm{s}$. In this figure, positive $\theta_{s}$ is in the forward scattering direction and negative $\theta_{s}$ is in the backward scattering direction. As expected, the maximum NRCS is at $\theta_{S}=50^{\circ}$, and the magnitude is larger for the lower wind condition with smoother surface roughness. The scattering beamwidth is narrower for the smoother surface roughness, so when $\theta_{s}$ is different from $\theta_{i}$ and with large $|\Delta \theta|$, the NRCS is larger in higher wind than that in lower wind. The $h h$ NRCS is larger than the $v v$ NRCS as a result of the larger $h h$ reflectivity compare to $v v$ (Figure 8). The SPT is basically following a geometric optics approach. A comparison of GO, small slope approximation (SSA), and two scale model (TSM) solutions is given in [70], here referred to as A06. Figure 3 of A06 is reproduced here as Figure 15b,c for 5 and $15 \mathrm{~m} / \mathrm{s}$, respectively. They give the results of SSA and GO comparison for the EM and wind conditions used in Figure 15a; the E97 spectrum [30] is used in the A06 analysis. Figure $15 \mathrm{c}$ can be compared with Figure $15 \mathrm{a} 5 \mathrm{~m} / \mathrm{s}$ results given with solid line $(h h)$ and circle marker ( $v v)$, and Figure 15d can be compared with Figure $15 \mathrm{a} 15 \mathrm{~m} / \mathrm{s}$ results given with dashed line $(h h)$ and square marker $(v v)$. There is a good quantitative and qualitative agreement between the SPT and GO results.
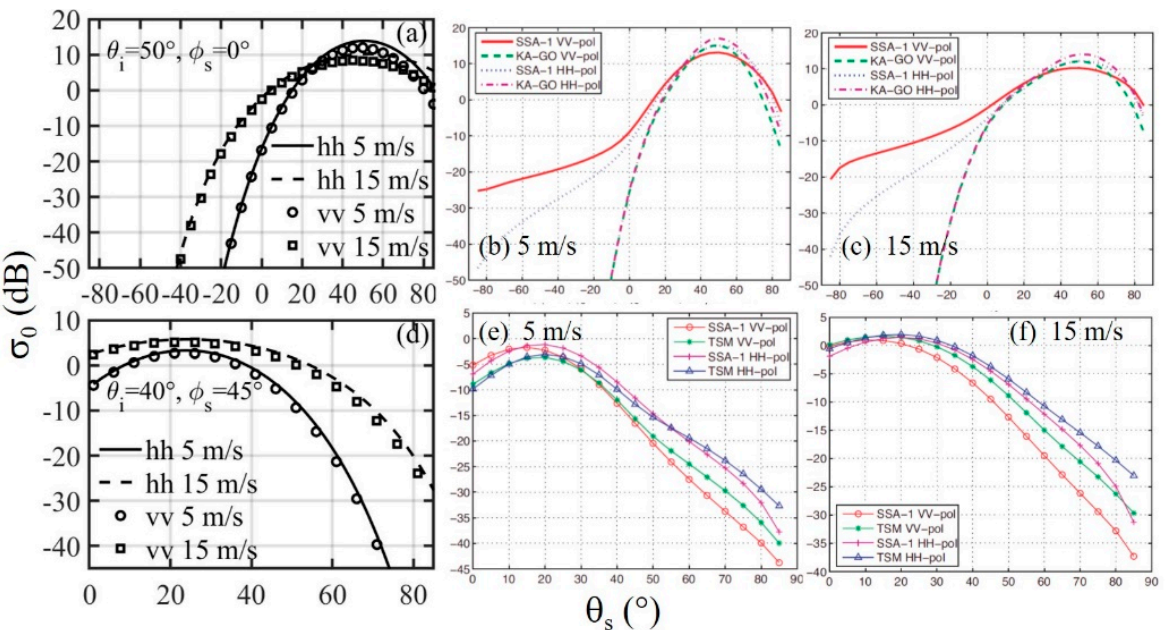

Figure 15. (Top row) Examples of in-plane NRCS dependence on $\theta_{s}, f=14 \mathrm{GHz}, \theta_{i}=50^{\circ}$. (a) Specular point computation, $U_{10}=5$ and $15 \mathrm{~m} / \mathrm{s}$, (b) $5 \mathrm{~m} / \mathrm{s}$, and (c) $15 \mathrm{~m} / \mathrm{s}$ SSA and GO solutions reproduced from Figure 3 of A06. (Bottom row) Examples of out-of-plane forward scattering $\left(\phi_{s}=45^{\circ}\right) \mathrm{NRCS}$ dependence on $\theta_{s}, f=14 \mathrm{GHz}, \theta_{i}=40^{\circ}$. (d) Specular point computation, $U_{10}=5$ and $15 \mathrm{~m} / \mathrm{s}$, (e) $5 \mathrm{~m} / \mathrm{s}$, and (f) $15 \mathrm{~m} / \mathrm{s}$ SSA and GO solutions reproduced from Figures 6a and 7a, respectively, of A06. 
Figure 15d shows the out-of-plane NRCS dependence on $\theta_{s}$ for $\theta_{i}=40^{\circ}$ and $\phi_{s}=45^{\circ}$. The high wind NRCS is larger than that of the low wind because of the broader beamwidth of scattering from the rougher surface. The SSA and TSM solutions for the conditions given in Figure 15d are given in Figures 6a and 7a of A06, which are reproduced as Figure 15e,f, respectively, for 5 and $15 \mathrm{~m} / \mathrm{s}$. The agreement between SPT and TSM or SSA is fair. The difference between SPT and TSM or SSA is comparable to the difference between TSM and SSA. All three produce similar results near the specular angle.

Figure 16a shows the NRCS dependence on the scattering azimuth angle $\phi_{s}$; the incidence and scattering elevation angles are fixed at $\theta_{i}=\theta_{S}=40^{\circ}$. The SPT gives a monotonically decreasing NRCS with respect to $\phi_{s}$, because the computed $\iota$ and $\gamma$ vary with $\phi_{s}$ monotonically. Figure 16b,c show the SSA and TSM solutions reproduced from Figure 8 of A06 for $U_{10}=5$ and $15 \mathrm{~m} / \mathrm{s}$, respectively. There is a lobe structure especially pronounced in the SSA solution. The SPT is not able to produce such a lobe variation in the scattering azimuthal dependence.
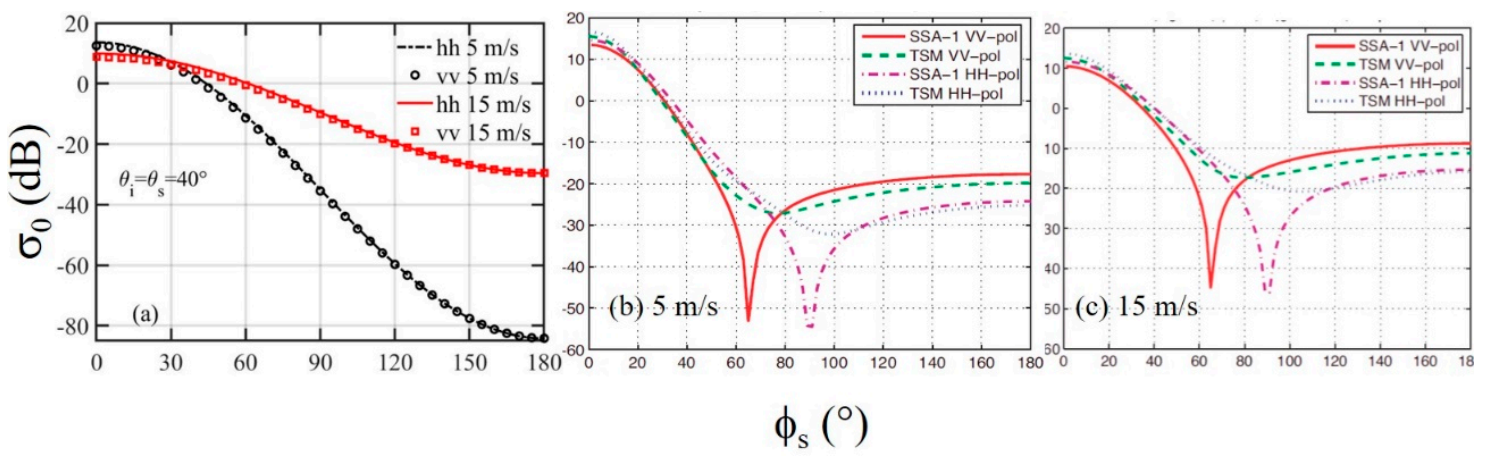

Figure 16. (a) Examples of NRCS dependence on $\phi_{s}, f=14 \mathrm{GHz}, \theta_{i}=\theta_{S}=40^{\circ}, U_{10}=5$ and $15 \mathrm{~m} / \mathrm{s}$; (b) and (c) are the SSA and TSM solutions reproduced from Figure 8 of A06 for $U_{10}=5$ and $15 \mathrm{~m} / \mathrm{s}$, respectively.

The GO approach (SPT included) is applied to very rough surface accounts for the large-scale roughness [71]. For nadir-looking (altimeter), it works well for small incidence angles, up to about $15^{\circ}$. As incidence angle increases, the Bragg scattering from small-scale roughness becomes important, and methods such as TSM, SSA, and small perturbation method (SPM) have been developed [8,70,72-74]. These models are used for forward computation of the scattering coefficients of the sea surface as a function of various parameters, such as the angles of incidence for different frequencies, polarizations, wind speeds, and wind directions. Others are dedicated to the inversion problems where empirical methods are usually used to estimate the wind speed and sea state from altimeters, scatterometers (including SAR images), and more recently the bistatic reflectometers such as the GNSSR $[23,24,75-79]$.

From the computed examples presented here, the SPT has been based on the geometric optics approach, has limited validity. Comparison with the GO, TSM, and SSA solutions suggests that the SPT works well for small $|\Delta \theta|=\left|\theta_{i}-\theta_{s}\right|$ and within a narrow azimuthal angle range in the forward specular scattering direction, estimated to be within about $\pm 10^{\circ}$ to $\pm 20^{\circ}$ in $|\Delta \theta|$ and $\left|\phi_{S}\right|\left(\phi_{i}=0^{\circ}\right)$. The applicable incidence angle range is unclear, but comparison with the SSA and TSM solutions [70] as shown in Figures 15 and 16 suggests that the SPT gives reasonable results near the specular reflection direction for incidence elevation angle up to about $50^{\circ}$ but maybe beyond, even to low grazing angle for the in-plane specular forward scattering condition $\left(\theta_{i}=\theta_{s}, \phi_{s}=0^{\circ}\right)$. Despite its limitation, the computation of SPT is relatively simple, and it elicits a clear connection between EM scattering and the ocean surface properties.

\section{Conclusions}

The specular point theory $[4-6,8]$ establishes a firm relationship between specular NRCS and surface wave statistical and geometric properties in a closed-form expression for 
a given $\gamma$ (7). Specifically, it states that the NRCS is linearly proportional to the reflectivity $\left|R_{\xi \eta}(l)\right|^{2}$, inversely proportional to the LPMSS $s_{f}^{2}$, and multiplied with a term dominated by the exponential attenuation with respect to the surface slope at the specular point $(\tan \gamma)$. To consider the local incidence angle modification, the left-hand side of Equation (6) is expressed as $\sigma_{0 \xi \eta}\left(\theta_{s}, \gamma\right)$. For small incidence and reflection angles, the modification of the local incidence angle can be significant as a result of the exponential term. To account for the local angle modification by the background tilting, a straightforward 2D Gaussian integration of Equation (6) is performed, which leads to Equation (14) for altimeters and Equation (15) for oblique reflectometers. The model results are in very good agreement with a broad collection of specular NRCS data from $\mathrm{L}, \mathrm{Ku}$, and $\mathrm{Ka}$ band instruments (Figures 11 and 12).

We emphasize that remote sensing measurements are indisputably among the most important data sources of ocean surface roughness. The satellite platforms allow data collection in extreme wind conditions from global oceans. Such capability is unimaginable for traditional in-situ ocean sensors. Since ocean remote sensing is interdisciplinary, it requires coherent consideration from both remote sensing and oceanographic perspectives in order to access this precious ocean data source for improving the ocean surface wave spectrum that is important to remote sensing analysis. In return, the improved ocean surface wave spectrum provides more accurate forward computations of microwave altimeters, reflectometers, scatterometers, and radiometers covering a wide range of frequencies, incidence angles, and polarizations. The study presented here offers a method to use specular microwave returns for understanding the mean square slopes of ocean surface roughness several times longer than the radar wavelengths. There are plenty of spaceborne altimeter and reflectometer measurements in existence. These measurements, coupled with the SPT, represent a valuable data source of the ocean surface wave properties covering a wide range of wind conditions. There are limitations associated with the general geometric optics approach. The applicable incidence angle range based on our comparison with SSA and TSM solutions suggests that the SPT gives good results near the specular reflection direction, within about $\pm 10^{\circ}$ to $\pm 20^{\circ}$ in $|\Delta \theta|=\left|\theta_{i}-\theta_{S}\right|$ and $\left|\phi_{S}\right|\left(\phi_{i}=0^{\circ}\right)$, for incidence elevation angle up to about $50^{\circ}$ but maybe beyond, even to low grazing angle for the in-plane specular forward scattering condition $\left(\theta_{i}=\theta_{s}, \phi_{s}=0^{\circ}\right)$. The SPT provides a clear physical interpretation between the microwave scattering from a rough surface and the statistic and geometric properties of the rough surface. The computation of SPT is relatively simple and the results presented here suggest its usefulness for the interpretation of satellite altimeter and reflectometer data for the purpose of retrieving the surface wave properties, particularly the LPMSS.

Author Contributions: Conceptualization: P.A.H., T.L.A., and J.D.O.; methodology: P.A.H., T.L.A., and J.D.O.; software: P.A.H.; validation: P.A.H., T.L.A., and J.D.O.; formal analysis: P.A.H., T.L.A., and J.D.O.; investigation: P.A.H., T.L.A., and J.D.O.; resources, P.A.H., T.L.A., and J.D.O.; data curation: P.A.H.; writing—original draft preparation: P.A.H.; writing—review and editing: P.A.H., T.L.A., and J.D.O.; visualization: P.A.H.; supervision: P.A.H., T.L.A., and J.D.O.; project administration: P.A.H., T.L.A., and J.D.O.; funding acquisition: T.L.A. and J.D.O. All authors have read and agreed to the published version of the manuscript.

Funding: This work is sponsored by the Office of Naval Research (Funding Doc. No. N0001416WX00044).

Institutional Review Board Statement: Not applicable.

Informed Consent Statement: Not applicable.

Data Availability Statement: Data sets used in this analysis are given in the references cited. The processing codes and data segments can also be obtained by contacting the corresponding author.

Conflicts of Interest: The funders had no role in the design of the study; in the collection, analyses, or interpretation of data; in the writing of the manuscript; or in the decision to publish the results. 


\section{References}

1. Crombie, D.D. Doppler Spectrum of Sea Echo at 13.56 Mc./s. Nature 1955, 175, 681-682. [CrossRef]

2. Wright, J.W. Backscattering from Capillary Waves with Application to Sea Clutter. IEEE Trans. Antennas Propag. 1966, 14, 749-754. [CrossRef]

3. Wright, J.W. A New Model for Sea Clutter. IEEE Trans. Antennas Propag. 1968, 16, 217-223. [CrossRef]

4. Kodis, R. A Note on the Theory of Scattering from an Irregular Surface. IEEE Trans. Antennas Propag. 1966, 14, 77-82. [CrossRef]

5. Barrick, D.E. Rough Surface Scattering Based on the Specular Point Theory. IEEE Trans. Antennas Propag. 1968, 16, 449-454. [CrossRef]

6. Barrick, D.E. Radar Clutter in an Air Defense System-I: Clutter Physics; TR DAAH01-67-C-1921; Battelle Memorial Institute: Columbus, OH, USA, 1968; p. 121.

7. Longuet-Higgins, M.S. The Statistical Analysis of a Random Moving Surface. Philos. Trans. R. Soc. Lond. 1957, A249, 321-387.

8. Valenzuela, G.P. Theories for the Interaction of Electromagnetic and Oceanic Waves-A Review. Bound. Layer Meteorol. 1978, 13, 61-85. [CrossRef]

9. Jackson, F.C.; Walton, W.T.; Hines, D.E.; Walter, B.A.; Peng, C.Y. Sea Surface Mean Square Slope from Ku-band Backscatter Data. J. Geophys. Res. 1992, 97, 11411-11427. [CrossRef]

10. Freilich, M.; Vanhoff, B. The Relationship between Winds, Surface Roughness, and Radar Backscatter at Low Incidence Angles from TRMM Precipitation Radar Measurements. J. Atmospheric Ocean. Technol. 2003, 20, 549-562. [CrossRef]

11. Cox, C.S.; Munk, W. Statistics of the Sea Surface Derived from Sun Glitter. J. Mar. Res. 1954, 13, $198-227$.

12. Bréon, F.M.; Henriot, N. Spaceborne Observations of Ocean Glint Reflectance and Modeling of Wave Slope Distributions. J. Geophys. Res. 2006, 111, C06005. [CrossRef]

13. Hwang, P.A.; Teague, W.J.; Jacobs, G.A.; Wang, D.W. A Statistical Comparison of Wind Speed, Wave Height and Wave Period Derived from Satellite Altimeters and Ocean Buoys in the Gulf of Mexico Region. J. Geophys. Res. 1998, 103, 10451-10468. [CrossRef]

14. Hwang, P.A.; Wang, D.W.; Teague, W.J.; Jacobs, G.A.; Wesson, J.; Burrage, D.; Miller, J. Anatomy of the Ocean Surface Roughness; NRL/FR/7330-02-10036; Naval Research Laboratory, Formal Rep: Washington, DC, USA, 2002; p. 45.

15. Hwang, P.A.; Burrage, D.; Wang, D.W.; Wesson, J. Ocean Surface Roughness Spectrum in High Wind Condition for Microwave Backscatter and Emission Computations. J. Atmospheric Ocean. Technol. 2013, 30, 2168-2188. [CrossRef]

16. Hwang, P.A.; Fois, F. Surface Roughness and Breaking Wave Properties Retrieved from Polarimetric Microwave Radar Backscattering. J. Geophys. Res. 2015, 120, 3640-3657. [CrossRef]

17. Hwang, P.A.; Fan, Y. Low-Frequency Mean Square Slopes and Dominant Wave Spectral Properties: Toward Tropical Cyclone Remote Sensing. IEEE Trans. Geosci. Remote Sens. 2018, 56, 7359-7368. [CrossRef]

18. Katzberg, S.J.; Dunion, J.P. Comparison of Reflected GPS Wind Speed Retrievals with Dropsondes in Tropical Cyclones. Geophys. Res. Lett. 2009, 36, L17602. [CrossRef]

19. Katzberg, S.J.; Dunion, J.P.; Ganoe, G.G. Comparison of Reflected GPS Wind Speed Retrievals with Dropsondes in Tropical Cyclones. Radio Sci. 2013, 48, 371-387. [CrossRef]

20. Gleason, S. Space Based GNSS Scatterometry: Ocean Wind Sensing Using Empirically Calibrated Model. IEEE Trans. Geosci. Remote Sens. 2013, 51, 4853-4863. [CrossRef]

21. Gleason, S.; Zavorotny, V.; Akos, D.; Hrbek, S.; PopStefanija, I.; Walsh, E.J.; Masters, D.; Grant, M. Study of Surface Wind and Mean Square Slope Correlation in Hurricane Ike with Multiple Sensors. IEEE J. Sel. Top. Appl. Earth Obs. Remote Sens. 2018, 11, 1975-1988. [CrossRef]

22. Clarizia, M.P.; Ruf, C.S. Wind Speed Retrieval Algorithm for the Cyclone Global Navigation Satellite System (CYGNSS) Mission. IEEE Trans. Geosci. Remote Sens. 2018, 54, 66-77. [CrossRef]

23. Ruf, C.S.; Balasubramaniam, R. Development of the CYGNSS Geophysical Model Function for Wind Speed. IEEE J. Sel. Top. Appl. Earth Obs. Remote Sens. 2019, 12, 66-77. [CrossRef]

24. Balasubramaniam, R.; Ruf, C. Azimuthal Dependence of GNSS-R Scattering Cross-Section in Hurricanes. J. Geophys. Res. 2020, 125, 12. [CrossRef]

25. Lillibridge, J.; Scharroo, S.; Abdalla, S.; Vandemark, D. One- and Two-Dimensional Wind Speed Models for Ka-Band Altimetry. J. Atmospheric Ocean. Technol. 2014, 31, 630-638. [CrossRef]

26. Guerin, C.-A.; Poisson, J.-C.; Piras, F.; Amarouche, L.; Lalaurie, J.C. Ku-/Ka-Band Extrapolation of the Altimeter Cross Section and Assessment with Jason2/AltiKa Data. IEEE Trans. Geosci. Remote Sens. 2017, 55, 5679-5686. [CrossRef]

27. Hwang, P.A.; Ainsworth, T.L. L-Band Ocean Surface Roughness. IEEE Trans. Geosci. Remote Sens. 2020, 58, 3988-3999. [CrossRef]

28. Hwang, P.A.; Fan, Y.; Ocampo-Torres, F.J.; García-Nava, H. Ocean Surface Wave Spectra inside Tropical Cyclones. J. Phys. Oceanogr. 2017, 47, 2393-2417. [CrossRef]

29. Hwang, P.A. Deriving L-Band Tilting Ocean Surface Roughness from Measurements by Operational Systems. IEEE Trans. Geosci. Remote Sens. 2021, in press. [CrossRef]

30. Elfouhaily, T.; Chapron, B.; Katsaro, K.; Vandemark, D. A Unified Directional Spectrum for Long and Short Wind-Driven Waves. J. Geophys. Res. 1997, 102, 15781-15796. [CrossRef]

31. Ruf, C.S.; Chang, P.S.; Clarizia, M.P.; Gleason, S.; Jelenak, Z.; Majumdar, S.J.; Morris, M.; Murray, J.; Musko, S.; Posselt, D.J.; et al. CYGNSS Handbook; University of Michigan Press: Ann Arbor, MI, USA, 2016. 
32. Zavorotny, V.U.; Gleason, S.; Cardellach, E.; Camps, A. Tutorial on Remote Sensing Using GNSS Bistatic Radar of Opportunity. IEEE Geosci. Remote Sens. Mag. 2014, 2, 8-45. [CrossRef]

33. Pierson, W.J.; Moskowitz, L. A Proposed Spectral Form for Fully Developed Wind Seas Based on the Similarity Theory of S. A. Kitaigorodskii. J. Geophys. Res. 1964, 69, 5181-5190. [CrossRef]

34. Hasselmann, K.; Barnett, T.P.; Bouws, E.; Carlson, H.; Cartwright, D.E.; Enke, K.; Ewing, J.A.; Gienapp, H.; Hasselmann, D.E.; Kruseman, P.; et al. Measurements of Wind-Wave Growth and Swell Decay during the Joint North Sea Wave Project (JONSWAP). Dtsch. Hydrogr. Z. 1973, A8, 1-95.

35. Hasselmann, K.; Ross, D.B.; Müller, P.; Sell, W. A Parametric Wave Prediction Mode. J. Phys. Oceanogr. 1976, 6, 200-228. [CrossRef]

36. Donelan, M.A.; Hamilton, J.; Hui, W.H. Directional Spectra of Wind-Generated Waves. Philos. Trans. R. Soc. Lond. 1985, A315, 509-562.

37. Klein, L.A.; Swift, C.T. An Improved Model for the Dielectric Constant of Sea Water at Microwave Frequencies. IEEE Trans. Antennas Propag. 1977, 25, 104-111. [CrossRef]

38. Meissner, T.; Wentz, F.J. Wind-Vector Retrievals under Rain with Passive Satellite Microwave Radiometers. IEEE Trans. Geosci. Remote Sens. 2009, 47, 3065-3083. [CrossRef]

39. Yueh, S.H.; Dinardo, S.J.; Fore, A.G.; Li, F.K. Passive and Active L-Band Microwave Observations and Modeling of Ocean Surface Winds. IEEE Trans. Geosci. Remote Sens. 2010, 48, 3087-3100. [CrossRef]

40. Yueh, S.H.; Tang, W.; Fore, A.G.; Neumann, G.; Hayashi, A.K.; Freedman, J.C.; Lagerloef, G.S.E. L-Band Passive and Active Microwave Geophysical Model Functions of Ocean Surface Winds and Applications to Aquarius Retrieval. IEEE Trans. Geosci. Remote Sens. 2013, 51, 4619-4632. [CrossRef]

41. Klotz, B.W.; Uhlhorn, E.W. Improved Stepped Frequency Microwave Radiometer Tropical Cyclone Surface Winds in Heavy Precipitation. J. Atmospheric Ocean. Technol. 2014, 31, 2392-2408. [CrossRef]

42. Meissner, T.; Wentz, F.J.; Ricciardulli, L. The Emission and Scattering of L-Band Microwave Radiation from Rough Ocean Surfaces and Wind Speed Measurements from the Aquarius Sensor. J. Geophys. Res. 2014, 119, 6499-6522. [CrossRef]

43. Reul, N.; Chapron, B.; Zabolotskikh, E.; Donlon, C.; Quilfen, Y.; Guimbard, S.; Piolle, J.F. A Revised L-Band Radio-Brightness Sensitivity to Extreme Winds under Tropical Cyclones: The Five Year SMOS-Storm Database. Remote Sens. Environ. 2016, 180, 274-291. [CrossRef]

44. Yueh, S.H.; Fore, A.G.; Tang, W.; Hayashi, A.K.; Stiles, B.W.; Reul, N.; Weng, Y.; Zhang, F. SMAP L-Band Passive Microwave Observations of Ocean Surface Wind during Severe Storms. IEEE Trans. Geosci. Remote Sens. 2016, 54, 7339-7350. [CrossRef]

45. Meissner, T.; Ricciardulli, L.; Wentz, F.J. Capability of the SMAP Mission to Measure Ocean Surface Winds in Storms. Bull. Am. Meteorol. Soc. 2017, 98, 1660-1677. [CrossRef]

46. Sapp, J.W.; Alsweiss, S.O.; Jelenak, Z.; Chang, P.S.; Carswell, J. Stepped Frequency Microwave Radiometer Wind-Speed Retrieval Improvements. Remote Sens. 2019, 11, 214. [CrossRef]

47. Hwang, P.A.; Reul, N.; Meissner, T.; Yueh, S.H. Whitecap and Wind Stress Observations by Microwave Radiometers: Global Coverage and Extreme Conditions. J. Phys. Oceanogr. 2019, 49, 2291-2307. [CrossRef]

48. Hwang, P.A.; Reul, N.; Meissner, T.; Yueh, S.H. Ocean Surface Foam and Microwave Emission: Dependence on Frequency and Incidence Angle. IEEE Trans. Geosci. Remote Sens. 2019, 57, 8223-8234. [CrossRef]

49. Birchak, J.R.; Gardner, L.G.; Hipp, J.W.; Victor, J.M. High Dielectric Constant Microwave Probes for Sensing Soil Moisture. Proc. IEEE 1974, 62, 93-98. [CrossRef]

50. Sihvola, A.H. Mixing Rules with Complex Dielectric Coefficients. Subsurf. Sens. Technol. Appl. 2000, 1, 393-415. [CrossRef]

51. Sihvola, A.H.; Kong, J.A. Effective Permittivity of Dielectric Mixtures. IEEE Trans. Geosci. Remote Sens. 1988, 26, 420-429. [CrossRef]

52. Wu, J. Near-Nadir Microwave Specular Returns from the Sea Surface-Altimeter Algorithms for Wind and Wind Stress. J. Atmospheric Ocean. Technol. 1992, 9, 659-667. [CrossRef]

53. Apel, J. An Improved Model of the Ocean Surface Wave Vector Spectrum and Its Effects on Radar Backscatter. J. Geophys. Res. 1994, 99, 16269-16291. [CrossRef]

54. Callahan, P.S.; Morris, C.S.; Hsiao, S.V. Comparison of TOPEX/POSEIDON Sigma0 and Significant Wave Height Distributions to Geosat. J. Geophys. Res. 1994, 99, 24369-24381.

55. Brown, G.S. Quasi-specular scattering from the air-sea interface. In Surface Waves and Fluxes; Kluwer Academic: Dordrecht, The Netherlands, 1990; Volume 2, pp. 1-40.

56. Brown, G.S.; Stanley, H.R.; Roy, N.A. The Wind Speed Measurement Capability of Spaceborne Radar Altimeters. IEEE J. Ocean. Eng. 1981, 6, 59-63. [CrossRef]

57. Chelton, D.B.; McCabe, P.J. A Review of Satellite Altimeter Measurement of Sea Surface Wind Speed; with a Proposed New Algorithm. J. Geophys. Res. 1985, 90, 4707-4720. [CrossRef]

58. Chelton, D.B.; Wentz, F.J. Further Development of an Improved Altimeter Wind Speed Algorithm. J. Geophys. Res. 1986, 91, 14250-14260. [CrossRef]

59. Witter, D.L.; Chelton, D.B. A Geosat Altimeter Wind Speed Algorithm and a Method for Altimeter Wind Speed Algorithm Development. J. Geophys. Res. 1991, 96, 8853-8860. [CrossRef]

60. Ebuchi, N.; Kawamura, H. Validation of Wind Speeds and Significant Wave Heights Observed by the TOPEX Altimeter around Japan. J. Oceanogr. 1994, 50, 479-487. [CrossRef] 
61. Freilich, M.H.; Challenor, P.G. A New Approach for Determining Fully Empirical Altimeter Wind Speed Model Functions. J. Geophys. Res. 1994, 99, 25051-25062. [CrossRef]

62. Gower, J.F.R. Intercomparison of Wave and Wind Data from TOPEX/POSEIDON. J. Geophys. Res. 1996, 101, 3817-3829. [CrossRef]

63. Abdalla, S. Ku-Band Radar Altimeter Surface Wind Speed Algorithm; TR 524, European Centre for Medium Range Weather Forecasts: Reading, UK, 2007; p. 18.

64. Ribal, A.; Young, I.R. 33 Years of Globally Calibrated Wave Height and Wind Speed Data Based on Altimeter Observations. Sci. Data 2019, 6, 1-19.

65. Willis, N.J. Bistatic Radar; SciTech Publishing: Raleigh, NC, USA, 2005; p. 329.

66. Willis, N.J.; Griffiths, H.D. Advances in Bistatic Radar; SciTech Publishing: Raleigh, NC, USA, 2007; p. 493.

67. Al-Ashwal, W.A.M. Measurement and Modelling of Bistatic Sea Clutter. Ph.D. Thesis, University College London, London, UK, 2011; p. 244.

68. Kabakchiev, K.H. Maritime Forward Scatter Radar: Data Collection and Clutter Analysis. Ph.D. Thesis, University of Birmingham, Birmingham, UK, 2014; p. 240.

69. Gashinova, M.; Kabakchiev, K.; Daniel, L.; Hoare, E.; Sizov, V.; Cherniakov, M. Measured Forward-Scatter Sea Clutter at near-Zero Grazing Angle: Analysis of Spectral and Statistical Properties. IET Radar Sonar Navig. 2014, 8, 132-141. [CrossRef]

70. Awada, A.; Ayari, Y.; Khenchaf, A.; Coatanhay, A. Bistatic Scattering from an Anisotropic Sea Surface: Numerical Comparison between the First-Order SSA and the TSM Models. Waves Random Complex Media 2006, 16, 383-394. [CrossRef]

71. Barrick, D.E.; Peake, W.H. Scattering from Surfaces with Different Roughness Scales: Analysis and Interpretation; TR BAT-197A-10-3; Battelle Memorial Institute: Columbus, OH, USA, 1967; p. 63.

72. Voronovich, A.G. Small-Slope Approximation for Electromagnetic Wave Scattering at the Rough Interface of Two Dielectric Half-Spaces. Waves Random Media 1994, 4, 337-367. [CrossRef]

73. Ayari, M.Y.; Khenchaf, A.; Coatanhay, A. Simulations of the Bistatic Scattering Using Two-Scale Model and the Unified Sea Spectrum. J. Appl. Remote Sens. 2007, 1, 013532. [CrossRef]

74. Voronovich, A.G. A Two-Scale Model from the Point of View of the Smallslope Approximation. Waves Random Media 1996, 6, 73-83. [CrossRef]

75. Hersbach, H.; Stoffelen, A.; de Haan, S. An Improved C-Band Scatterometer Ocean Geophysical Model Function: CMOD5. J. Geophys. Res. 2007, 112, C03006. [CrossRef]

76. Hwang, P.A.; Stoffelen, A.; van Zadelhoff, G.-J.; Perrie, W.; Zhang, B.; Li, H.; Shen, H. Cross Polarization Geophysical Model Function for C-Band Radar Backscattering from the Ocean Surface and Wind Speed Retrieval. J. Geophys. Res. 2015, 120, 893-909. [CrossRef]

77. Stoffelen, A.; Adriaan, J.; Verspeek, V.; Vogelzang, J.; Verhoef, A. The CMOD7 Geophysical Model Function for ASCAT and ERS Wind Retrievals. IEEE J. Sel. Top. Appl. Earth Obs. Remote Sens. 2017, 10, 2023-2134. [CrossRef]

78. La, T.V.; Khenchaf, A.; Comblet, F.; Nahum, C. Assessment of Wind Speed Estimation from C-Band Sentinel-1 Images Using Empirical and Electromagnetic Models. IEEE Trans. Geosci. Remote Sens. 2018, 56, 4075-4087. [CrossRef]

79. La, T.V.; Messager, C.; Honnorat, M.; Sahl, R.; Khenchaf, A. Use of Sentinel-1 C-Band SAR Images for Convective System Surface Wind Pattern Detection. J. Appl. Meteorol. Climatol. 2020, 59, 1321-1332. [CrossRef] 